Published in final edited form as:

Cancer Res. 2012 September 15; 72(18): 4682-4695. doi:10.1158/0008-5472.CAN-12-0440.

\title{
INK4a/ARF inactivation with activation of the NF-KB/IL-6 pathway is sufficient to drive the development and growth of angiosarcoma
}

\author{
Jinming Yang ${ }^{1,2}$, Sara Kantrow ${ }^{3}$, Jiqing Sai ${ }^{1,2}$, Oriana Hawkins ${ }^{1,2}$, Mark Boothby ${ }^{4}$, Gregory \\ D Ayers $^{5}$, Eric Young ${ }^{6}$, Elizabeth Demicco ${ }^{7}$, Alex Lazar ${ }^{7}$, Dina Lev ${ }^{6}$, and Ann Richmond ${ }^{1,2}$ \\ ${ }^{1}$ Veterans Affairs Medical Center, Nashville, TN \\ ${ }^{2}$ Department of Cancer Biology, Vanderbilt University School of Medicine, Nashville, Tennessee \\ 37232, USA \\ ${ }^{3}$ Division of Dermatology, Department of Medicine, Vanderbilt University School of Medicine, \\ Nashville, Tennessee 37232, USA \\ ${ }^{4}$ Department of Pathology, Microbiology and Immunology, Vanderbilt University School of \\ Medicine, Nashville, Tennessee 37232, USA \\ ${ }^{5}$ Division of Cancer Biostatistics, Department of Biostatistics, Vanderbilt University School of \\ Medicine, Nashville, Tennessee 37232, USA \\ ${ }^{6}$ Departments of Surgical Oncology and Cancer Biology, MD Anderson Cancer Center, Houston, \\ TX 77030 \\ ${ }^{7}$ Department of Pathology, MD Anderson Cancer Center, Houston, TX 77030
}

\begin{abstract}
Although human angiosarcoma has been associated frequently with mutational inactivation of the tumor suppressor gene Ink4a/Arf, the underlying mechanisms have not been delineated. Here we report that malignant angiosarcoma is associated with high levels of RelA/NF- $\kappa B$ and IL-6, in contrast to normal vessels or benign hemagiomas. Studies of Ink4a/Arf deficient mice not only recapitulate genetic traits observed in human angiosarcoma but also unveil a possible therapeutic link comprised of the NF-kB/IL-6/Stat3 signaling axis. In Ink4a/Arf-/- cells, NF- $\kappa$ B controlled Stat 3 signaling by transcriptionally controlling the expression of IL-6, gp130 and Jak2. Further, IL-6 mediated Stat 3 signaling through the sIL-6R. Inhibition of Ikk $\beta$ solely in myeloid cells was insufficient to block angiosarcoma development; in contrast, systemic inhibition of Ikk $\beta$, IL-6, or Stat3 markedly inhibited angiosarcoma growth. Our findings offer clinical implications for targeting the NF-kB/IL-6/STAT3 pathway as a rational strategy to treat angiosarcoma.
\end{abstract}

\section{Keywords}

inhibitor of $\mathrm{kB}$ kinase; p16/p19; interleukin-6; angiosarcoma

\footnotetext{
Correspondence Author: Ann Richmond, Department of Cancer Biology, Vanderbilt University School of Medicine, Nashville, Tennessee 37232, USA. Phone: 615.343.7777; Fax: 616.936.2911. ann.richmond@ vanderbilt.edu.

Disclosure of Potential Conflicts of Interest

No potential conflicts of interests were disclosured.
} 


\section{Introduction}

Angiosarcoma is a malignant vascular tumor of endothelial origin. There has been an increase in angiosarcomas over the last 30 years. This type of sarcoma is known to have an extremely high mortality rate $(\sim 79-83 \%)$ due to rapid growth and metastasis $(1-4)$. Lesions are thought to arise from the transformation of endothelial cells that are resident within tissues or from circulating stem cells recruited from bone marrow or sites of extra-medullary hematopoiesis $(5,6)$. Though the exact etiology of angiosarcoma is unknown, many diverse environmental factors are linked to its development.

Genetic mutations or gene amplifications for VEGF, MDM2, p53, Ras, Myc have been investigated in a large number of clinical angiosarcoma tissues (7-9), but the genetic changes identified are complex (10). In human primary angiosarcoma, the INK4a/ARFlocus on human chromosome $9 \mathrm{p} 21$ encoding cycle-regulatory proteins, $\mathrm{p} 16^{\mathrm{INKa}}$ and $\mathrm{p} 14^{\mathrm{ARF}}$, is frequently disrupted by either deletion of the locus or methylation of the promoter $(11,12)$. Over-expression of $\mathrm{p} 16^{\mathrm{INK} 4 \mathrm{a}}$ leads to senescence, while loss of $\mathrm{p} 16^{\mathrm{INK} 4 \mathrm{a}}$ results in immortalization in human cells $(13,14)$. The ARF tumor suppressor (p14 ${ }^{\mathrm{ARF}}$ in human, $\mathrm{p} 19^{\mathrm{ARF}}$ in mouse) activates $\mathrm{p} 53(15,16)$. Of interest, $\mathrm{p} 53$ is frequently mutated in human angiosarcoma (4). Loss of p53 links to enhanced activation of NF- $\mathrm{kB}$ just as methylation of ARF results in failure to induce p53 and resultant enhanced NF- $\mathrm{kB}$ mediated transcription.

Aberrant NF- $\kappa \mathrm{B}$ is associated with tumorigenesis, angiogenesis and metastasis (17).

Moreover, apart from effects of the NF- $\kappa$ B pathway intrinsic to the developing tumor cells, it is increasingly clear that the tumor microenvironment and its leukocyte infiltrate can have antitumor or pro-tumor effects. One major target gene transcriptionally regulated by NF- $\mathrm{KB}$ is IL-6, a cytokine produced and released by a variety of cell types including macrophages, fibroblasts, endothelial cells, T cells, and B cells, which are frequently associated with enhanced tumor growth. IL-6 secretion by angiosarcoma lesions has been associated clinically with locally aggressive behavior and metastasis (18). Moreover, phosphorylation of STAT3 is common in cutaneous angiosarcoma lesions (19) and tumors with constitutive NF- $\mathrm{KB}$ activation often exhibit constitutive phosphorylation of STAT3, potentially through an IL-6 stimulated event (20) In spite of these findings, the underlying molecular links between genetic alteration and malignancy have not been defined.

In the study described herein, we observed strong activation of the NF- $\kappa \mathrm{B} / \mathrm{IL}-6 / \mathrm{STAT} 3$ pathway in human hemangioma and angiosarcoma lesions. Using INK4a/ARF null FVB mice that recapitulate genetic and molecular events of angiosarcoma tumorigenesis, we asked how regulating between NF- $\mathrm{\kappa B}$ and STAT3 signal pathways and targeting of the NF$\kappa \mathrm{B}$ pathway, specifically in angiosarcoma tumor cells versus myeloid cells, would affect growth of angiosarcoma lesions as compared to systemic inhibition of NF- $\mathrm{\kappa B}$ using a small molecule Ikk $\beta$ inhibitor.

\section{Materials and Methods}

\section{Murine models of angiosarcoma, myeloid Ikk $\beta$ knockout and Cre reporter}

Detailed breeding and genotyping are included in Supplemental Methods. Animal care and use procedures were followed according to the protocols approved by the Institutional Animal Care and Use Committee, Department of Animal Care, Vanderbilt University.

\section{Flow cytometry}

To characterize the distribution of immune cells in the tumor microenvironment, a single cell suspension was obtained after enzymatic digestion of the primary angiosarcoma tissues of Ikk $\beta^{\mathrm{wt}}$ or Ikk $\beta^{\Lambda / \Delta}$ mice. Cells were stained and analyzed by flow cytometry by a BD 
LSRII FACScan flow cytometry and analyzed using the BD FACSDiva program (for details see Supplemental Methods

\section{Tumor induced myeloid cell chemoattraction assay in vivo}

A single cell suspension of angiosarcoma cells $\left(1 \times 10^{7}\right.$ cell/mouse) killed by heating to $55^{\circ} \mathrm{C}$ for $30 \mathrm{~min}$ or by fixation in $2 \%$ paraformaldehyde for $10 \mathrm{~min}$ was injected intraperitoneally into Ikk $\beta^{\Delta / \Delta}$ mice, or into control Ikk $\beta^{\text {wt }}$ mice. Eighteen hours after injection, the leukocytes infiltrating into the peritoneum were collected, counted and stained with fluorochrome-conjugated antibodies, followed by flow cytometry analysis as described above.

\section{Total RNA extraction, cDNA synthesis, and quantitation by real-time PCR}

Total RNA was extracted using the RNeasy Mini Kit (Qiagen), and cDNA synthesis was performed using SuperScript III First-Strand Synthesis System (Invitrogen) according to the manufacturer's instructions. Real-time quantitative PCR was performed with the BioRad CFX-qPCR instrument using the SsoFast EvaGreen Supermix assay (BioRad), with $\beta$-actin serving as a control gene (see Supplemental Methods for detailed protocols). Two-tailed Student's $t$-tests were performed to calculate the statistical significance of the $\Delta \mathrm{Ct}$ between Ikk $\beta$ wild type and Ikk $\beta$ deleted samples. Primers were used in this study are in the Supplemental Methods.

\section{Neutralization of IL-6 in vitro and in vivo}

For in vitro neutralization, $5 \times 10^{4}$ angiosarcoma cells/ml/well (12-well plate) were cultured in DMEM/F-12 medium containing 1\% FBS and with increasing concentrations (0-1000 ng/ $\mathrm{ml}$ ) of IL-6 antibody (Clone number MP5-20F3, R\&D Systems). Subsequently $200 \mu \mathrm{l}$ of protein A/G Plus-agarose (Santa Cruz Biotechnology, Inc.) was added and samples were rotated overnight at $4^{\circ} \mathrm{C}$ to remove IL-6. IL-6 protein was detected by ELISA (R\&D System, Minneapolis, MN). The antibody concentration that totally removed the IL-6 in the conditioned medium was used as the "neutralizing antibody concentration". For in vivo neutralization, FVB strain mice with subcutaneous inoculated angiosarcoma cells $\left(1 \times 10^{7}\right)$ were administrated $500 \mu \mathrm{g}$ of rat antibody to mouse IL- 6 by intraperitoneal injection twice weekly for 3 weeks. Matched control mice $(n=5)$ received the same concentration of rat $\operatorname{IgG1}$

\section{Cytokine array and ELISA assay}

Cytokine array using RayBiotech mouse cytokine antibody array G series 2 Kit (32 cytokines, RayBiotech Inc) and ELISA assay for IL-6 (R\&D Systems) were performed as previously described (21) (see Supplemental Methods for details).

\section{Assessment of cell apoptosis and death}

The percentage of early stage apoptotic cells was evaluated using the Total Cytotoxicity Kit (Immunochemistry Technologies, LLC) according to the manufacturer's directions. The early apoptotic cells are defined as those that are SR-FLICA ${ }^{\mathrm{TM}}$ positive, but 7-AAD negative.

\section{Nitric oxide (NO) assay}

The NO content in peripheral blood and angiosarcoma containing blood was determined using the QuantiChrom Nitric Oxide Assay kit (DINO-250, Bioassay Systems) following the manufacture's protocol. 


\section{Western blotting assay}

Immunoblotting analyses of cytoplasmic extracts from cultured primary angiosarcoma cells were performed as previously described (21).

\section{NF- KB promoter reporter construct and luciferase activity assay}

NF- $\mathrm{kB}$ transcription factor binding sites in the promoters of GP130 and Jak2 were identified using the program at http://www.cbrc.jp/research/db/TFSEARCH.html. Three copies of the gene specific NF- $\kappa \mathrm{B}$ promoter sequence from the JAK2 or gp130 promoters were cloned into a Gaussian luciferase reporter and activity assays were performed after transient transfection using protocols detailed in Supplemental Methods

\section{Statistical analyses}

Data are expressed as mean \pm SEM with sample size per experimental group specified. Prism software (GraphPad), SAS (Statistical Analysis System), and R were used for statistical analyses and graphics. Unless specified otherwise, the two-sample t-test with Satterthwaite's approximation was used to determine the statistical difference between two independent experimental groups. The cumulative incidence of spontaneous angiosarcoma between groups was calculated using the method of Kaplan and Meier and compared using the log-rank statistic. A two-sided p-value $₫ \mathbf{} 0.05$ was considered to indicate a significant difference between groups.

\section{Results}

\section{RelA/p65 is highly expressed in benign and malignant human vascular tumors}

Human vascular tissue microarray from US Biomax and M.D. Anderson Cancer Center (University of Texas) were examined for NF- $\mathrm{kB} / \mathrm{p} 65$, IL-6, CD31, and pSTAT3 protein expression in samples of 10 normal blood vessels, 55 benign hemangiomas, and 55 angiosarcomas. Tissues were obtained with informed consent according to the IRB guidelines of the M.D. Anderson Cancer Center. Immunofluorescence was quantitated in relation to nuclear or cytoplasmic staining with DAPI visualization of nuclei. Strong expression of p65 was seen in 10\% of normal blood vessels, which increased to $49 \%$ in benign hemangiomas $(p=0.034)$, and $58 \%$ in angiosarcoma $(p=0.006)$. Neither nuclear pSTAT3 staining nor strong IL-6 was expressed in normal blood vessels, while $33 \%$ of the benign hemangiomas exhibited strong nuclear pSTAT3 staining $(p=0.05)$ and $30 \%$ of angiosarcomas ( $\mathrm{p}=0.097$ ) exhibited strong IL-6 expression (Fig. 1). Thus, $\mathrm{p} 65$ expression is present in normal vascular tissue and increases with neoplastic and malignant transformation, which is associated with the increased IL-6 expression and nuclear STAT3 translocation in the transforming or transformed lesion. However, our observation that high levels of IL-6 and pSTAT3 were not simultaneously expressed in the same type of lesion indicates the complexity of signal transduction pathway activation during angiosarcoma development.

\section{Ink4a/Arf null mice recapitulate human angiosarcoma}

Ink4a/Arf deficiency in mice has been shown to be associated with the development of fibrosarcoma, lymphoma and angiosarcoma lesions $(22,23)$. Sharpless et al demonstrated that angiosarcoma is a common tumor for animal germline deficient for both p16INK4a and p53 (24). In prior studies we observed that loss of Ink4a/Arf in C57B1/6 mice resulted in a high incidence of spontaneous lymphoma and fibrosarcoma lesions (25). In the study described herein we observed that the FVB strain of Ink4a/Arf-/- mice exhibits a high incidence of angiosarcoma lesions, with an approximate incidence of 30\% within 100 days. Once the angiosarcoma lesions are visible, they grow rapidly, while tumors did not develop 
in the wild type Ink4a/Arf FVB mice. The angiosarcomas in Ink4a/Arf-/- mice occur in association with the vasculature of muscle, liver, lung, chest wall, spleen, intestine and skin (Fig. 2A a-g, respectively). Splenic angiosarcoma (Fig. 2Ae) was associated with greatly enlarged spleen. The splenic angiosarcomas frequently undergo metastasis to liver (Fig. 2Ah). Histological H\&E staining of angiosarcoma primary lesions arising in subcutaneous muscle tissue, spleen, liver and lung (Fig. 2B a-d, respectively) shows lesions are comprised of large islands of blood cells, in sharp contrast to the normal tissues of liver (Fig. 2Be) and lung (Fig. 2Bf). Angiosarcoma lesions exhibit vasculature disorder but stain positive for Von Willebrand Factor (VWF) (Fig. 2Ca) and CD31 (Fig. 2Cc), consistent with poorly differentiated angiosarcoma in patients $(4,26,27)$. Lesional staining for VWF is contrasted to the staining of intact blood vessels in lung (Fig. 2Cb).

The formation of angiosarcoma lesions has been associated with reduced expression of inhibitors of angiogenesis and enhanced expression of angiogenic factors such as IL-8, IL-6, VEGFA, and bFGF (5). Serum cytokines in angiosarcoma bearing versus non-tumor bearing mice were examined with a G Series 232 cytokine array. Serum IL- 6 was $11 \pm 2.5$ fold higher in tumor bearing compared to tumor-free mice $(n=6$ Fig. 2D) and this was the sole cytokine present at significantly different levels in tumor bearing versus non-tumor bearing mice. Analysis of the IL-6 levels in angiosarcoma tumor tissue, as compared to adjacent non-tumor muscle tissue, spleen, bone marrow and thymus, revealed very high levels of IL-6 in angiosarcoma lesions compared to adjacent ( $869 \pm 165 \mathrm{vs} 10 \pm 2.6 \mathrm{pg} / \mathrm{g}$ protein, $\mathrm{n}=6$ )

(Fig. 2E). IL-6 has been shown to activate endothelial progenitor cells and play a crucial role in angiogenesis and vascular remodeling in vitro and in vivo $(28,29)$. Thus it is plausible that IL-6 contributes to transformation of endothelium into malignant angiosarcoma when Ink4a/Arf is deleted, recapitulating genetic traits of human angiosarcoma.

\section{IL-6 is required for tumor growth}

Angiogenesis and vasculogenesis are supported by cytokine mediated cross-talk between tumor cells and endothelial cells in the tumor microenvironment. To evaluate the role of tumor secretion of IL-6 on tumor cell viability, IL-6 antibody or control isotype IgG was added to cultured angiosarcoma cells in increasing concentrations to neutralize secreted IL-6 (Fig. 3A). The treated cells were then collected, stained with SR-FLICA and subjected to FACS analysis to determine the \% apoptotic cells. Treatment with 100 and $1000 \mathrm{ng} / \mathrm{ml}$ IL-6 antibody $(p<0.01)$ markedly increased the $\%$ apoptotic cells compared with $\mathrm{IgG}$ controls (Fig. 3B) and induced cell death, based 7-AAD staining (Fig. S1A) $(p<0.01)$.

To investigate whether anti-IL-6 induced apoptosis in vivo and affected tumor progression, angiosarcoma cells were subcutaneously inoculated into FVB mice. When tumor size reached around $180 \mathrm{~mm}^{3}$, mice received anti-IL-6 antibody or the same amount of isotype IgG antibody as a control $(30,31)$, After 6 days treatment, the anti-IL-6 treatment induced apoptosis as indicated by the cleaved PARP, but not in IgG control treatment (Fig. 3C), reduced cell proliferation (Fig. S2C) and reduced tumor volume 1.9 ( $<<0.01, \mathrm{n}=6$, Fig. S1B). In another series of experiments, mice were treated with antibody immediately following tumor transplant. After three weeks of treatment, the tumor volume in IL-6 Ab treated animals was 4-fold reduced in comparison tumor grafts of $\operatorname{IgG}$ control treated animals $\left(188 \pm 69 \mathrm{~mm}^{3}\right.$ versus $\left.792 \pm 151 \mathrm{~mm}^{3}, p<0.01\right)$ (Fig. S1C and S1D). Antibody neutralization of IL-6 in the blood of tumor-bearing mice was confirmed by ELISA $(26.4 \pm 25.6 \mathrm{pg} / \mathrm{ml}$ in IL-6 antibody treated versus $676 \pm 118 \mathrm{pg} / \mathrm{ml}$ in IgG treated mice (Fig. S1E). Anti-IL-6 not only induced apoptosis, but also reduced NF- $\mathrm{BB}$ transcriptional activity based upon luciferase reporter signaling in angiosarcoma cells $(\mathrm{p}<0.01, \mathrm{n}=6$, Fig. S1F).

To learn the impact of anti-IL-6 impact on the cytokine profile, serum samples from mice described in Fig. S1B were subjected to cytokine array (Fig. 3D). After 6 days treatment, the 
serum cytokine profile was analyzed using a cytokine array (32 cytokines) approach. The value of cytokines was compared to the serum sample from a tumor-free mouse and expressed as fold-change. Results showed the active form of IL-12, p40, was markedly elevated in tumor bearing mice compared to non-tumor bearing mice (24-fold for IgG1 versus 49-fold anti-IL-6), and this elevation was 2-fold higher in mice treated with anti-IL-6 as compared to those treated with control IgG1. Other serum cytokines were elevated in tumor bearing mice IgG1 treated mice compared to non-tumor bearing mice, but anti-IL-6 antibody reduced the elevation: RANTES ( 8.9 vs 2.8 fold); IL-6 (7.9 vs 0.1 fold); and MCP-5 (6.6 vs 0.8 fold), as indicated in Fig. 3D. The IL-6 in the serum of tumor-bearing mice was biologically active based on induction of Stat 3 phosphorylation in splenic cells (Fig. S2A). Moreover, the levels of phosphorylated Stat3 declined when IL-6 was neutralized by IL-6 antibody (Fig. S2B). Not surprisingly, neutralization of IL-6 statistically impacted the tumor infiltrating immune cells by decreasing the macrophage population $(p=0.044)$, increasing B cells $(p=0.012)$, and increasing CD4+ T cells $(p=0.028)$, in comparison with the IgG1 isotype control group ( $\mathrm{n}=6$, Student's t-test). There were no significant changes on the neutrophils $(\mathrm{p}=0.139)$ or $\mathrm{CD} 8+\mathrm{T}$ cells $(\mathrm{p}=0.187)$ between the treated and control animal tumors (Fig S2D). Data here revealed that tumor-secreted IL-6 is not only a major effector on angiosarcoma growth through inhibitory apoptosis, but also is a regulator in tumor immunity. Since IL-6 is transcriptionally regulated in part by NF- $\kappa B$, we asked whether inhibition of NF- $\mathrm{kB}$ might effectively inhibit IL- 6 expression and angiosarcoma growth.

\section{Targeting Ikk $\beta$ in angiosarcoma cells reduces IL- 6 and IL- 6 mediated signaling}

Disruption of the Ink4a/Arf gene may be causally linked to angiosarcoma through an NF- $\mathrm{kB}$ dependent mechanism since $\mathrm{p} 16^{\mathrm{INK} 4 \mathrm{a}}$ and $\mathrm{p} 19^{\mathrm{ARF}}$ are negative regulators of NF- $\kappa \mathrm{B}$, positive regulators of p53 (32), and act as inhibitors of cyclin-dependent kinases (33). To determine how depletion of Ikk $\beta$ would affect angiosarcoma cells, knockdown of $I k k \beta$ was performed by stable expression of a lentiviral shRNA targeting Ikk $\beta$. With this approach, $95 \%$ of the Ikk $\beta$ protein was knocked down while Ikk $\gamma$ was intact (Fig. 4A). When Ikk $\beta$ was knocked down in the angiosarcoma cells there was a decline in p65 phosphorylation on Ser-536, Stat3 phosphorylation on Tyr-705, and membrane gp130 expression, while p53 protein levels increased (Fig. 4A).

Silencing Ikk $\beta$ in cultured angiosarcoma cells abrogated IL-6 secretion into the medium $(4.7 \pm 4.6 \mathrm{pg} / \mathrm{ml}, p<0.01, \mathrm{n}=3)$, in contrast to IL-6 $(2233 \pm 235 \mathrm{pg} / \mathrm{ml})$ secreted from the same number of angiosarcoma cells with intact Ikk $\beta$ protein (Fig. 4B). Of interest, silencing of I $k$ k $a$ did not affect IL-6 secretion $(2755 \pm 369 \mathrm{pg} / \mathrm{ml}$ versus $2233 \pm 235, \mathrm{p}=0.17, \mathrm{n}=3)$ by angiosarcoma cells. Thus, Ikk $\beta$ is an important mediator in the NF- $\mathrm{kB}$ pathway that is also essential for IL-6 production by angiosarcoma.

\section{NF-kB directly regulates intrinsic gp130/Jak2/Stat3 expression}

Since Ikk $\beta$ interference reduced phosphorylation of Stat3 in angiosarcoma cells (Fig. 4A), we asked whether Ikk $\beta / \mathrm{NF}-\kappa \mathrm{B}$ signaling impacted the intrinsic expression of gp130, Jak2 or the sIL-6R. Toward this end, cell surface gp130 was examined by FACS. Silencing Ikk $\beta$ in angiosarcoma cells resulted in $92.8 \%$ reduction of cell membrane gp130 (Fig. 4C) that was accompanied by a $91 \%$ reduction gp130 protein based upon Western blot (Fig. 4D), a marked suppression of gp130mRNA based upon qRT-PCR (15.6 fold) (Fig. 4E), and a dramatic inhibition of gp130 NF- $\mathrm{kB}$ mediated promoter activity, p<0.05) (Fig. 4F). Similarly, silencing Ikk $\beta$ in angiosarcoma cells resulted in an $89 \%$ reduction in JAK2 protein (Fig. 4G), a 26.8-fold reduction in JAK2 mRNA (Fig. 4H), and dramatic reduction in the JAK2 NF- $\kappa B$ regulated promoter activity, $\mathrm{p}<0.01$ (Fig. $4 \mathrm{I}$ ) Thus, constitutive activity of 
the Stat3 pathway in angiosarcoma cells is tightly controlled by Ikk $\beta / \mathrm{NF}-\kappa \mathrm{B}$ signaling through intrinsic transcription regulation of gp130/Jak2.

\section{NF-KB regulates extrinsic IL-6 signaling through sIL-6R, but not IL-6R}

Since there is no detectable IL-6Ra expressed by the angiosarcoma cells (data not shown), we evaluated expression of the soluble IL-6 receptor (sIL-6Ra), which like the IL-6Ra can interact with gp130 to initiate signaling in response to IL-6. We determined that the major source of the sIL-6Ra is from mouse blood $(848 \pm 198 \mathrm{pg} / \mathrm{ml}$, Fig. $4 \mathrm{~J})$ while angiosarcoma cells secrete a more modest quantity of the sIL-6Ra $(126 \pm 8.5 \mathrm{pg} / \mathrm{ml}$, Fig. $4 \mathrm{~K})$. There was no detectable sIL-6Ra in the serum-containing medium not exposed to the angiosarcoma cells. These data show that disruption of Ikk $\beta$ reduced expression of the sIL-6Ra in vitro and in vivo.

\section{NF-KB is required for angiosarcoma growth}

Human tissue microarray shows that RelA/p65 is highly expressed in benign and malignant human vascular tumors (Fig. 1). Angiosarcoma cells depleted of IKK $\beta$ through expression of the IKK $\beta$ shRNA grew $~ 4.5$ times slower in vitro than cells expressing the non-silencing shRNA (Fig. 5A), indicating that Ikk $\beta$ is crucial for the growth of Ink4a/Arf ${ }^{/-}$ angiosarcoma cells. However, the reduction in cell growth in response to knockdown of Ikk $\beta$ led to the slow cell growing in vitro was not associated with enhanced apoptosis ( $\mathrm{p}=0.53$, Fig. 5B). To determine whether similar effects in vitro would be observed in vivo, FVB mice were subcutaneously injected with Ink4a/Arf deficient angiosarcoma cells stably expressing lentiviral shRNA Ikk $\beta$ or shRNA empty vector as a control. Three weeks after injection of cells, angiosarcomas lesions were observed in all control mice, but no tumors were observed in mice injected with Ikk $\beta$-depleted angiosarcoma cells (Fig. 5C), indicating that Ikk $\beta$ is crucial for angiosarcoma tumorigenesis resulting from deficiency of $\mathrm{p} 16^{\text {Ink4a/ }}$

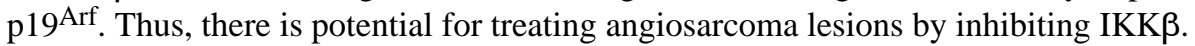
However, since IKK $\beta$ also affects the anti-tumor or pro-tumor capacity of tumor associated myeloid cells (34), it was important to access how loss of IKK $\beta$ would affect the myeloid cells in angiosarcoma tumor bearing mice.

\section{IKK $\beta$ depletion in angiosarcoma reduces migration response of myeloid cells}

Bone marrow myeloid cells were isolated from wild type FVB mice and evaluated for chemotactic response to conditioned medium from IKK $\beta$ expressing or IKK $\beta$ depleted angiosarcoma cells. Flow cytometry data indicate that the population of purified bone marrow cells consisted of 38\% B cells, 21\% PMN and immature myeloid cells, $8 \%$ macrophages, $4 \%$ dendritic cells and $29 \%$ other types of cells, such as stroma cells, stem cells, and endothelial cells. These cells showed robust chemotaxis in response to medium conditioned by Ikk $\beta$ expressing and IKK $\beta$ deficient angiosarcoma cells, but medium from Ikk $\beta$ expressing angiosarcoma cells produced a much stronger chemotactic response (Fig. $\mathrm{S} 3 \mathrm{~A})$. There was no obvious difference in cell migration in response to increasing concentrations of murine IL- 6 , suggesting chemotaxis in response to conditioned medium is due to secretion of NF- $\kappa$ B regulated factors other than IL-6 (Fig. S3B).

\section{Deletion of Ikk $\beta$ in myeloid cells increases incidence of angiosarcoma}

Cells of the myeloid lineage, especially mononuclear phagocytes, are crucial for establishment of innate immunity and cytokine regulation of acquired immune responses (35). Moreover, it has been reported that NF- $\mathrm{kB}$ regulates the shift of immune cells from an anti-tumor to a pro-tumor phenotype(34). To determine the role of NF- $\kappa \mathrm{B}$ in myeloid cells on the immune response to the tumor we disrupted $\operatorname{Ikk} \beta$ only in myeloid cells by breeding mice carrying loxP-flanked Ikk $\beta$ allele with LysMCre mice in which the Cre-recombinase is 
expressed under the control of the murine lysozyme-M gene regulatory region (Fig. 6A). Upon breeding of FVB-LysMCre mice to FVB mice harboring lox $P$-flanked target genes, these animals efficiently undergo Cre-lox $P$-mediated recombination in macrophages and neutrophils, but not in B and T cells or in the majority of dendritic cells (36). To examine the efficiency of LysMCre mediated deletion of the $I o x P$-flanked $I k k \beta$ allele in tumor tissue, Ikk $\beta^{\text {wt }}$ (LysMCre::Ink4a/Arf-/-) mice were bred with $\mathrm{mT} / \mathrm{mG}$ (membrane-Tomato/ membrane-Green) mice to obtain an additional genomic background of Gt(Rosa)26Sortm4(ACTB-tdTomato-EGFP) in which the loxP-flanked tdTomato following the EGFP (mG) cassette was inserted into the Gt(ROSA)26Sor locus. These $\mathrm{mT} / \mathrm{mG}$ mice served as a Cre-reporter strain (37). Myeloid cells from mice carrying this insertion shift fluorescence from red to green after Cre-mediated recombination to yield green IKK $\beta-/-$ myeloid cells. The GFP-positive infiltrated cells were sorted from angiosarcomas lesions arising in 4 mice with a background of homogenous $\mathrm{mT} / \mathrm{mG}$, positive for LysMCre, and deficient for Ink4a/Arf genes, using specific cell marker antibodies noted in Methods. The percentage of GFP positive cells infiltrating the tumor reflects the specificity and efficiency of the LysMCre mediated Ikk $\beta$ deletion in the cells (Fig. S3C).

To examine the impact of myeloid Ikk $\beta$ on angiosarcoma development in Ink4a/Arf null mice, tumor incidence was recorded in $63 \operatorname{Ikk} \beta^{\Delta / \Delta}\left(\operatorname{Ikk} \beta^{\mathrm{f} / \mathrm{f}}::\right.$ LysMCre::Ink4a/Arf-/-) mice and $73 \mathrm{Ikk} \beta^{\mathrm{wt}}$ (LysMCre::Ink4a/Arf-/-) mice over a four-month period. There was a significant increase in the cumulative incidence of angiosarcoma (48\%) in $\operatorname{Ikk} \beta^{\Delta / \Delta}$ mice when compared with that $(27 \%, p<0.01)$ in the control Ikk $\beta^{\mathrm{wt}}$ animals (Fig. 6B). Moreover, the latency of angiosarcoma arising in $I k k \beta^{\Delta / \Delta}$ mice ( $89 \pm 17$ days, $n=31$ of 63) was shorter than in $I k k \beta^{w t}$ mice (103 \pm 17 days, $\mathrm{n}=20$ of 73 ) (Table $\mathrm{S} 1$ ). Thus, myeloid Ikk $\beta$ positively contributes to anti-tumor immunity in this mouse tumor model.

\section{Myeloid Ikk $\beta$ contributes to anti-tumor immunity}

The percentage of tumor-infiltrating neutrophils (CD45+CD11b+Ly6G+) was significantly lower in angiosarcoma tissues of $\operatorname{Ikk} \beta^{\Delta / \Delta}$ mice than in $\operatorname{Ikk} \beta^{\mathrm{wt}}$ mice $(\mathrm{p}<0.01, \mathrm{n}=5)($ Fig. $5 \mathrm{C})$. However, there was no statistical difference between tumor-bearing $\operatorname{Ikk} \beta^{\mathrm{wt}}$ and $\operatorname{Ikk} \beta^{\Delta / \Delta}$ mice for tumor-infiltrating macrophages (CD45+CD11b+Ly6G-), dendritic cells (CD45+CD11C+), B cells (CD45+B220+) and T cells (CD45+CD4+, CD45+CD8a+) (Fig. $6 \mathrm{C}$ and $6 \mathrm{D})$. Tumor infiltrating immunocytes can produce toxic products such as nitric oxide (NO) to kill tumor cells. To determine whether NO release by infiltrating myeloid cells is important in this mouse angiosarcoma model, NO levels were determined in the peripheral blood and tumor blood of mice. Measurements of NO in both peripheral and intra-tumoral blood revealed lower levels of $\mathrm{NO}$ in $\operatorname{Ikk} \beta^{\Delta / \Delta}$ mice as compared to $\operatorname{Ikk} \beta^{\mathrm{wt}}$ counterparts (Fig. 6E), implying that neutrophil-derived NO contributions to host antitumor response were blunted when myeloid cells lacked IKK $\beta$. To investigate the impact of myeloid Ikk $\beta$ on tumor cell viability in vivo, angiosarcoma cells derived from primary angiosarcoma of FVB mouse deficient for Ink4a/Arf were genetically engineered to stably express nonsecreted Gaussian luciferase (18-285aa). These cells were injected intraperitoneally into $\mathrm{Ikk} \beta^{\mathrm{wt}}$ or LysM-Cre Ikk $\beta^{\Delta / \Delta}$ mice. Eighteen hours after injection, peritoneal cells were collected, lysed and the luciferase activity was determined. Enhanced tumor cell survival, as reflected by an increase in luciferase activity, indicates a reduction in anti-tumor activity of recipient host with deletion of myeloid Ikk $\beta$ (Fig. 6F). Thus neutrophil-derived NO contributions to host antitumor response were blunted when myeloid cells lacked IKK $\beta$. These data indicate that infiltrated cells play an important role in tumor immunity through a mechanism involving NO. 


\section{Myeloid Ikk $\beta$ is required for CD11b+ cell cytotoxicity in angiosarcoma}

To investigate the pro-tumor mechanism of $\mathrm{CD} 11 \mathrm{~b}+$ cells null for Ikk $\beta$, the intra-tumoral neutrophils and macrophages were sorted by flow cytometry and the intracellular cytokine profile was examined. Deletion of myeloid Ikk $\beta$ resulted in elevated IL-4 and reduced IL-12 and IFN $\gamma$ in both neutrophils and macrophages ( $p<0.01, \mathrm{n}=3)$ (Fig. S4A and B).

Simultaneously, cellular arginase I increased 3.8-fold in neutrophils ( $\mathrm{p}=0.024, \mathrm{n}=5$, by $\mathrm{t}$-test) and 6.3 -fold in macrophages ( $\mathrm{p}=0.011, \mathrm{n}=4$, by $\mathrm{t}$-test), compared with $\mathrm{Ikk} \beta$ wild type cells (Fig. S4C). Together, these data indicate that intact Ikk $\beta$ in myeloid cells is necessary for the anti-tumor phenotype of myeloid cells in this angiosarcoma model. Moreover, data suggest that loss of IKK $\beta$ in myeloid cells results in a shift to the N2/M2 pro-tumorigenic type of leukocytes, with enhanced tumor growth.

\section{Systemic inhibition of IKK $\beta$ inhibits growth of angiosarcoma tumors in vivo}

A need for intrinsic NF- $\kappa \mathrm{B}$ for angiosarcoma formation suggests that IKK $\beta$ is a promising therapeutic target. However, the anti-tumorigenic effects of IKK $\beta$ in myeloid cells raised the issue of which role for IKK $\beta$ would predominate if small molecule IKK $\beta$ inhibitors were used. To address this question, we systemically delivered BMS-345541, a highly selective inhibitor of Ikk $\beta$, to mice bearing angiosarcoma xenografts. When the tumor size reached $\sim 250 \mathrm{~mm}^{3}$ ( 2 weeks post implantation), mice were treated with $75 \mathrm{mg} / \mathrm{kg}$ BMS-345541 twice per day and the control tumor bearing mice received a similar volume of vehicle only. After one week of drug treatment, tumor growth of the BMS treated mice was significantly reduced compared to vehicle treated controls $\left(307 \pm 80 \mathrm{~mm}^{3}\right.$ versus $548 \pm 119 \mathrm{~mm}^{3}$, respectively, $p<0.01, \mathrm{n}=10$ ). A similar result was obtained after two weeks treatment, where tumor volume was $392 \pm 88 \mathrm{~mm}^{3}$ versus $1098 \pm 200 \mathrm{~mm}^{3}$ in treated versus control, respectively (mean \pm SEM, $p<0.01$, Student's t-test) (Fig. 7A). Upon systemic targeting Ikk $\beta$ with BMS345541, the angiosarcoma tumor tissue showed obvious nuclear apoptotic features, in sharp contrast to control tumors treated with vehicle alone (Fig. 7B). Moreover, IL-6 levels markedly declined with systemic BMS345541 treatment (Fig. 7C) and results in reduced response to exogenous IL-6 through reduced expression of gp130 and Jak2 (Fig. $7 \mathrm{E})$. In addition, inhibition of Ikk $\beta$ by BMS-345541 resulted in reduction of Stat3 phosphorylation in immune cells (Fig. S5A). Knockdown of Stat3 in angiosarcoma cells (Fig. S5B) was associated with the reduced IL-6 production (Fig. S5C). Systemic inhibition of Stat3 with $10 \mathrm{mg} / \mathrm{kg} \mathrm{S31-201}$ achieved anti-tumor activity, as evidenced by $71 \%$ inhibition of tumor growth ( $\mathrm{p}<0.01, \mathrm{n}=6$, Fig. S5D). Thus, Ikk $\beta$ appears to be a potential target for treatment of angiosarcoma lesions especially since systemic inhibition of IKK $\beta$ overcomes the tumor promoting phenotype observed when IKK $\beta$ is deleted only in myeloid cells (Fig. 7D).

\section{Discussion}

In work we described here, a genetically modified mouse model was utilized to recapitulate genetic and epigenetic events that characterize human malignant angiosarcoma and to provide insight for new therapeutic strategies for treatment of malignant angiosarcoma. Immunofluorescent analysis of tissue microarrays of human blood vessels, benign hemangioma, and malignant angiosarcoma lesions reveal a trend toward higher levels of expression of RelA/p65 and IL-6 in metastatic angiosarcoma. High expression of RelA/p65 and IL-6 are accompanied by nuclear localization of phospho-STAT3. In this study, disruption of Ink4a/Arf genes in FVB mice is associated with spontaneous angiosarcoma formation in multiple organs and metastasis with activation of the Ikk $\beta / \mathrm{NF}-\kappa \mathrm{B} / \mathrm{IL}-6 / \mathrm{Stat} 3$ pathway, thus recapitulating major traits seen in human angiosarcoma lesions. Knocking down $I k k \beta$ or antagonizing IL-6 in cells from spontaneously arising angiosarcoma resulted in a dramatic anti-tumor effect. Moreover, systemic inhibition of the NF- $\mathrm{kB}$ pathway 
allowed suppression of the NF- $\mathrm{kB} / \mathrm{IL}-6 / \mathrm{STAT} 3$ signaling pathway and inhibition of tumor growth. Surprisingly, when $I k k \beta$ was deleted only in myeloid cells, angiosarcoma growth was enhanced and the myeloid cells that infiltrated the tumor exhibited a pro-tumor or M2like phenotype. This provides the first clear demonstration that activation of the NF- $\mathrm{KB}$ pathway in myeloid cells is important for the anti-tumor M1-like phenotype. However, since systemic inhibition of Ikk $\beta$ effectively inhibited tumor growth, our data indicate that NF- $\mathrm{kB}$ activity in other cells is required for the tumor promoting effect of Ikk-/- myeloid cells. Our data offer hope for new therapies for angiosarcoma patients and new insights into the role of $\mathrm{NF}-\mathrm{\kappa B}$ in regulation of immune response to tumor.

Mouse angiosarcoma cells produce a large amount of IL- 6 and mice with angiosarcoma exhibit elevated serum IL-6, mimicking the high serum IL-6 in angiosarcoma patients, which was speculated to be as associated with clinical malignancy, angiogenesis, vascular remodeling, and metastasis (18). The human IL-6 gene (5kb) is located on chromosome 7 p20 and the IL- 6 promoter contains a NF- $\mathrm{KB}$ binding site between nucleotides 75-63 upstream of the IL-6 mRNA (38). Inflammatory factors can activate NF- $\kappa$ B to drive IL-6 production (39). Constitutive activation of NF- $\kappa \mathrm{B}$ has been observed frequently in a variety of malignant cancers, including melanoma, breast cancer, colon cancer, leukemia, lymphoma, myeloma, and HNSCC(40). The aberrant NF- $\kappa \mathrm{B}$ activity is often associated with the hyper-expression of IL-6 $(41,42)$. We observed that Ikk $\beta$, but not Ikka, is responsible for the IL- 6 production in the angiosarcoma cells, based upon our finding that stable knockdown of Ikk $\beta$ in the angiosarcoma cells blocks IL-6 production and release, while knockdown of Ikka enhances IL-6 secretion by angiosarcoma cells in vitro. Similarly, inhibition of NF- $\kappa$ B by the super-repressor of I $\kappa$ B (S32/36A) abrogated the IL-6 paracrine activation of STAT3 in HNSCC cells (41). Moreover, when Ikk $\beta$ was knocked-down in angiosarcoma cells in vitro, there was a reduction in expression of gp130 and the sIL-6R by angiosarcoma cells and exogenous IL-6 failed to induce phosphorylation of p65 at Ser 536 and phosphorylation of Stat3. These data are in agreement with prior work showing a strong link between IKK $\beta$ and IL- 6 in tumorigenesis in colon, hepatocellular, pancreatic and esophageal carcinomas $(43,44)$. Thus, our combined data indicate that Ikk $\beta$ is vital for the IL-6 autocrine/paracrine activation of Stat 3 and NF- $\kappa B$ in angiosarcoma. Moreover, we provide key novel data showing that the mechanism by which suppression of Ikk $\beta$ results in a reduced response to exogenous IL-6 is through reduced expression of gp130 and Jak2 (Fig. $7 \mathrm{E})$.

Mounting evidence indicates that inflammation promotes malignant transformation. In the cancer microenvironment, cross-talk between cancer cells and infiltrating immune cells is linked by both extrinsic (cytokine mediated paracrine or autocrine) and intrinsic (gene mutation) pathways. In this mouse model NF- $\mathrm{kB} / \mathrm{IL}-6 / \mathrm{Stat} 3$ signaling becomes a major extrinsic pathway for cancer inflammation in association with an intrinsic loss of $\mathrm{p} 16^{\text {Ink4a }}$ p19Arf. IL-6 drives Jak mediated activation of Stat3, presumably in both angiosarcoma cells and in immune cells recruited into the tumor microenvironment. NF- $\kappa B$ activity is maintained by the feed-forward (autocrine) loop. Thus, both NF- $\kappa B$ and Stat 3 have central and integrated roles in the inflammation of cancer. These transcription factors are involved in both pro-carcinogenic inflammation and in anti-tumor immune responses (45). Here we show that myeloid Ikk $\beta$ is linked to anti-tumor immunity. Moreover, in the in vivo tumor mediated myeloid chemotaxis assay, deletion of myeloid Ikk $\beta$ also impairs the migration of both neutrophils and macrophages. Thus, NF- $\mathrm{kB}$ and Stat 3 interact at multiple levels during tumorigenesis.

The clinical prognosis for angiosarcoma is poor and current therapeutic options offer limited hope. There is a crucial need for an effective therapy. Recent phase II clinical trials targeting of Raf/MAPK pathway with Sorafenib (46) and BCR-ABL/VEGF pathway with Imatinib 
(47) have been conducted in patients with advanced or metastatic angiosarcoma. The efficacy was limited, with response rates between $12 \%$ and $13 \%$. Large clinical trials with the chemotherapeutic agents doxorubicin $(26,48)$ and taxane $(49)$ show only transient or ineffective responses in metastatic angiosarcoma. We observed that targeting Ikk $\beta$ systemically with small molecule inhibitor or with antibody to IL-6 in angiosarcoma bearing immunocompetent mice resulted in dramatic reduction of tumor growth. Together with other evidence that IL-6/Stat3/HIF plays major role in human clear carcinoma (50), data presented here support the Ikk $\beta / \mathrm{NF}-\kappa \mathrm{B} / \mathrm{IL}-6 / \mathrm{Stat} 3$ pathway as novel molecular targets for angiosarcoma therapy and enhance our understanding of how disrupting the balance between IKK/NF- $\mathrm{KB}$ in tumor and inflammatory cells promotes tumor development and growth.

\section{Supplementary Material}

Refer to Web version on PubMed Central for supplementary material.

\section{Acknowledgments}

We thank Linda W. Horton, Krystle Fordyce and Melissa Downing for excellent technical assistance and immunostaining. We thank Michael Karin (UCSD) for plasmids of pLSLPw shRNA Ikka and Ikk $\beta$ and for the IKK $\beta$ floxed mice, Lynda Chen (DFCI) for the INK4a/ARF null mice, and Li Yang and Hal Moses for the LysMCre mice. This work was supported by research grants from the NIH: CA 116021 (AR), and 5P30CA068485 and a Merit Award the Department of Veterans Affairs (AR) and a VA Senior Research Career Scientist Award (AR).

\section{References}

1. Mark RJ, Poen JC, Tran LM, Fu YS, Juillard GF. Angiosarcoma. A report of 67 patients and a review of the literature. Cancer. 1996; 77:2400-2406. [PubMed: 8635113]

2. Lahat G, Dhuka AR, Hallevi H, Xiao L, Zou C, Smith KD, et al. Angiosarcoma: clinical and molecular insights. Ann Surg. 251:1098-1106. [PubMed: 20485141]

3. Naka N, Ohsawa M, Tomita Y, Kanno H, Uchida A, Aozasa K. Angiosarcoma in Japan. A review of 99 cases. Cancer. 1995; 75:989-996. [PubMed: 7842420]

4. Naka N, Ohsawa M, Tomita Y, Kanno H, Uchida A, Myoui A, et al. Prognostic factors in angiosarcoma: a multivariate analysis of 55 cases. J Surg Oncol. 1996; 61:170-176. [PubMed: 8637202]

5. Cohen SM, Storer RD, Criswell KA, Doerrer NG, Dellarco VL, Pegg DG, et al. Hemangiosarcoma in rodents: mode-of-action evaluation and human relevance. Toxicol Sci. 2009; 111:4-18. [PubMed: 19525443]

6. Young RJ, Brown NJ, Reed MW, Hughes D, Woll PJ. Angiosarcoma. Lancet Oncol. 2010; 11:983991. [PubMed: 20537949]

7. Zietz C, Rossle M, Haas C, Sendelhofert A, Hirschmann A, Sturzl M, et al. MDM-2 oncoprotein overexpression, p53 gene mutation, and VEGF up-regulation in angiosarcomas. Am J Pathol. 1998; 153:1425-1433. [PubMed: 9811333]

8. Przygodzki RM, Finkelstein SD, Keohavong P, Zhu D, Bakker A, Swalsky PA, et al. Sporadic and Thorotrast-induced angiosarcomas of the liver manifest frequent and multiple point mutations in Kras-2. Lab Invest. 1997; 76:153-159. [PubMed: 9010458]

9. Manner J, Radlwimmer B, Hohenberger P, Mossinger K, Kuffer S, Sauer C, et al. MYC high level gene amplification is a distinctive feature of angiosarcomas after irradiation or chronic lymphedema. Am J Pathol. 176:34-39. [PubMed: 20008140]

10. Wong KF, So CC, Wong N, Siu LL, Kwong YL, Chan JK. Sinonasal angiosarcoma with marrow involvement at presentation mimicking malignant lymphoma: cytogenetic analysis using multiple techniques. Cancer Genet Cytogenet. 2001; 129:64-68. [PubMed: 11520569]

11. Weihrauch M, Markwarth A, Lehnert G, Wittekind C, Wrbitzky R, Tannapfel A. Abnormalities of the ARF-p53 pathway in primary angiosarcomas of the liver. Hum Pathol. 2002; 33:884-892.

[PubMed: 12378512] 
12. Tannapfel A, Weihrauch M, Benicke M, Uhlmann D, Hauss J, Wrbitzky R, et al. p16INK4Aalterations in primary angiosarcoma of the liver. J Hepatol. 2001; 35:62-67. [PubMed: 11495043]

13. Reznikoff CA, Yeager TR, Belair CD, Savelieva E, Puthenveettil JA, Stadler WM. Elevated p16 at senescence and loss of p16 at immortalization in human papillomavirus $16 \mathrm{E} 6$, but not E7, transformed human uroepithelial cells. Cancer Res. 1996; 56:2886-2890. [PubMed: 8674033]

14. Sharpless NE, Bardeesy N, Lee KH, Carrasco D, Castrillon DH, Aguirre AJ, et al. Loss of p16Ink4a with retention of p19Arf predisposes mice to tumorigenesis. Nature. 2001; 413:86-91. [PubMed: 11544531]

15. Zhang Y, Xiong Y, Yarbrough WG. ARF promotes MDM2 degradation and stabilizes p53: ARFINK4a locus deletion impairs both the Rb and p53 tumor suppression pathways. Cell. 1998; 92:725-734. [PubMed: 9529249]

16. Rocha S, Campbell KJ, Perkins ND. p53- and Mdm2-independent repression of NF-kappa B transactivation by the ARF tumor suppressor. Mol Cell. 2003; 12:15-25. [PubMed: 12887889]

17. Baldwin AS. Control of oncogenesis and cancer therapy resistance by the transcription factor NFkappaB. J Clin Invest. 2001; 107:241-246. [PubMed: 11160144]

18. Soo J, Arif S, Kidd BL, Jawad AS. Pyrexia, pelvic pain and thrombocytopenia in an Asian man with Paget's disease of bone. Rheumatology (Oxford). 2004; 43:110-111. [PubMed: 14681565]

19. Chen SY, Takeuchi S, Urabe K, Hayashida S, Kido M, Tomoeda H, et al. Overexpression of phosphorylated-ATF2 and STAT3 in cutaneous angiosarcoma and pyogenic granuloma. J Cutan Pathol. 2008; 35:722-730. [PubMed: 18700251]

20. Grivennikov S, Karin E, Terzic J, Mucida D, Yu GY, Vallabhapurapu S, et al. IL-6 and Stat3 are required for survival of intestinal epithelial cells and development of colitis-associated cancer. Cancer Cell. 2009; 15:103-113. [PubMed: 19185845]

21. Yang J, Splittgerber R, Yull FE, Kantrow S, Ayers GD, Karin M, et al. Conditional ablation of Ikkb inhibits melanoma tumor development in mice. The Journal of clinical investigation. 2010; 120:2563-2574. [PubMed: 20530876]

22. Serrano M, Lee H, Chin L, Cordon-Cardo C, Beach D, DePinho RA. Role of the INK4a locus in tumor suppression and cell mortality. Cell. 1996; 85:27-37. [PubMed: 8620534]

23. Sharpless NE, Ramsey MR, Balasubramanian P, Castrillon DH, DePinho RA. The differential impact of p16(INK4a) or p19(ARF) deficiency on cell growth and tumorigenesis. Oncogene. 2004; 23:379-385. [PubMed: 14724566]

24. Sharpless NE, Alson S, Chan S, Silver DP, Castrillon DH, DePinho RA. p16(INK4a) and p53 deficiency cooperate in tumorigenesis. Cancer research. 2002; 62:2761-2765. [PubMed: 12019151]

25. Yang J, Luan J, Yu Y, Li C, DePinho RA, Chin L, et al. Induction of melanoma in murine macrophage inflammatory protein 2 transgenic mice heterozygous for inhibitor of kinase/alternate reading frame. Cancer Res. 2001; 61:8150-8157. [PubMed: 11719444]

26. Meis-Kindblom JM, Kindblom LG. Angiosarcoma of soft tissue: a study of 80 cases. Am J Surg Pathol. 1998; 22:683-697. [PubMed: 9630175]

27. Maddox JC, Evans HL. Angiosarcoma of skin and soft tissue: a study of forty-four cases. Cancer. 1981; 48:1907-1921. [PubMed: 7197190]

28. Fan Y, Ye J, Shen F, Zhu Y, Yeghiazarians Y, Zhu W, et al. Interleukin-6 stimulates circulating blood-derived endothelial progenitor cell angiogenesis in vitro. J Cereb Blood Flow Metab. 2008; 28:90-98. [PubMed: 17519976]

29. McClintock JY, Wagner EM. Role of IL-6 in systemic angiogenesis of the lung. J Appl Physiol. 2005; 99:861-866. [PubMed: 15905327]

30. Gregory MS, Faunce DE, Duffner LA, Kovacs EJ. Gender difference in cell-mediated immunity after thermal injury is mediated, in part, by elevated levels of interleukin-6. J Leukoc Biol. 2000; 67:319-326. [PubMed: 10733091]

31. Poutahidis T, Haigis KM, Rao VP, Nambiar PR, Taylor CL, Ge Z, et al. Rapid reversal of interleukin-6-dependent epithelial invasion in a mouse model of microbially induced colon carcinoma. Carcinogenesis. 2007; 28:2614-2623. [PubMed: 17724375] 
32. Becker TM, Rizos H, de la Pena A, Leclercq IA, Woodruff S, Kefford RF, et al. Impaired inhibition of NF-kappaB activity by melanoma-associated p16INK4a mutations. Biochem Biophys Res Commun. 2005; 332:873-879. [PubMed: 15913553]

33. Serrano M, Hannon GJ, Beach D. A new regulatory motif in cell-cycle control causing specific inhibition of cyclin D/CDK4. Nature. 1993; 366:704-707. [PubMed: 8259215]

34. Hagemann T, Lawrence T, McNeish I, Charles KA, Kulbe H, Thompson RG, et al. "Re-educating" tumor-associated macrophages by targeting NF-kappaB. The Journal of experimental medicine. 2008; 205:1261-1268. [PubMed: 18490490]

35. Silva MT. Neutrophils and macrophages work in concert as inducers and effectors of adaptive immunity against extracellular and intracellular microbial pathogens. J Leukoc Biol. 2010; 87:805-813. [PubMed: 20110444]

36. Clausen BE, Burkhardt C, Reith W, Renkawitz R, Forster I. Conditional gene targeting in macrophages and granulocytes using LysMcre mice. Transgenic Res. 1999; 8:265-277. [PubMed: 10621974]

37. Muzumdar MD, Tasic B, Miyamichi K, Li L, Luo L. A global double-fluorescent Cre reporter mouse. Genesis. 2007; 45:593-605. [PubMed: 17868096]

38. Ray A, Tatter SB, May LT, Sehgal PB. Activation of the human "beta 2-interferon/hepatocytestimulating factor/interleukin 6" promoter by cytokines, viruses, and second messenger agonists. Proceedings of the National Academy of Sciences of the United States of America. 1988; 85:6701-6705. [PubMed: 3045822]

39. Karin M, Lin A. NF-kappaB at the crossroads of life and death. Nat Immunol. 2002; 3:221-227. [PubMed: 11875461]

40. Basseres DS, Baldwin AS. Nuclear factor-kappaB and inhibitor of kappaB kinase pathways in oncogenic initiation and progression. Oncogene. 2006; 25:6817-6830. [PubMed: 17072330]

41. Squarize CH, Castilho RM, Sriuranpong V, Pinto DS Jr, Gutkind JS. Molecular cross-talk between the NFkappaB and STAT3 signaling pathways in head and neck squamous cell carcinoma. Neoplasia. 2006; 8:733-746. [PubMed: 16984731]

42. Zerbini LF, Wang Y, Cho JY, Libermann TA. Constitutive activation of nuclear factor kappaB p50/p65 and Fra-1 and JunD is essential for deregulated interleukin 6 expression in prostate cancer. Cancer Res. 2003; 63:2206-2215. [PubMed: 12727841]

43. Maeda S, Hikiba Y, Sakamoto K, Nakagawa H, Hirata Y, Hayakawa Y, et al. Ikappa B kinasebeta/ nuclear factor-kappaB activation controls the development of liver metastasis by way of interleukin-6 expression. Hepatology. 2009; 50:1851-1860. [PubMed: 19821485]

44. Li N, Grivennikov SI, Karin M. The Unholy Trinity: Inflammation, Cytokines, and STAT3 Shape The Cancer Microenvironment. Cancer Cell. 2011; 19:429-431. [PubMed: 21481782]

45. Yu H, Kortylewski M, Pardoll D. Crosstalk between cancer and immune cells: role of STAT3 in the tumour microenvironment. Nat Rev Immunol. 2007; 7:41-51. [PubMed: 17186030]

46. Maki RG, D'Adamo DR, Keohan ML, Saulle M, Schuetze SM, Undevia SD, et al. Phase II study of sorafenib in patients with metastatic or recurrent sarcomas. J Clin Oncol. 2009; 27:3133-3140. [PubMed: 19451436]

47. Chugh R, Wathen JK, Maki RG, Benjamin RS, Patel SR, Meyers PA, et al. Phase II multicenter trial of imatinib in 10 histologic subtypes of sarcoma using a bayesian hierarchical statistical model. J Clin Oncol. 2009; 27:3148-3153. [PubMed: 19451433]

48. Fayette J, Martin E, Piperno-Neumann S, Le Cesne A, Robert C, Bonvalot S, et al. Angiosarcomas, a heterogeneous group of sarcomas with specific behavior depending on primary site: a retrospective study of 161 cases. Ann Oncol. 2007; 18:2030-2036. [PubMed: 17974557]

49. Penel N, Marreaud S, Robin YM, Hohenberger P. Angiosarcoma: state of the art and perspectives. Critical reviews in oncology/hematology. 2011; 80:257-263. [PubMed: 21055965]

50. Anglesio MS, George J, Kulbe H, Friedlander M, Rischin D, Lemech C, et al. IL6-STAT3-HIF signaling and therapeutic response to the angiogenesis inhibitor sunitinib in ovarian clear cell cancer. Clinical cancer research. 2011; 17:2538-2548. [PubMed: 21343371] 


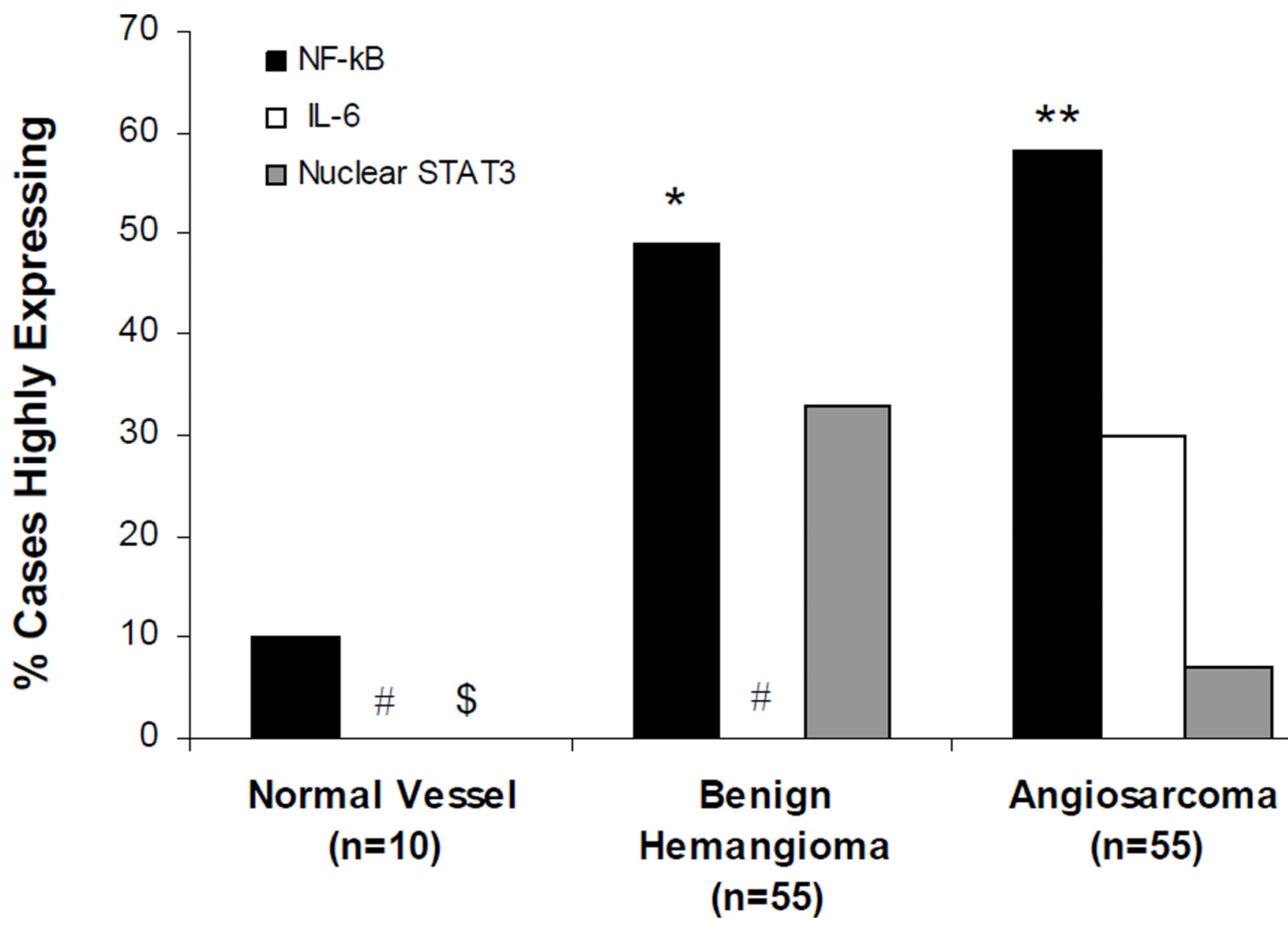

Figure 1.

Over-expression of NF- kB/IL-6/pSTAT3 in human angiosarcoma lesions. Human tissue microarray slides including normal vessels, benign, malignant lesions were stained with specific RELA/p65 or IL-6 or phospho-STAT3 (Tyr705) antibody and Alexafluor 555conjugated second antibodies. The fluorescent intensity was scored as 1 to 3 to reflect low, moderate or strong expression of the protein studied. Graphs indicate percentage of cases of each lesion type with the high level expression(score $=3$ ). Statistical analysis of $\%$ lesions with high expression compared to normal vessel is shown with $* p<0.05, * * p<0.01$. \#, undetectable IL-6. \$, undetectable nuclear STAT3. 
A
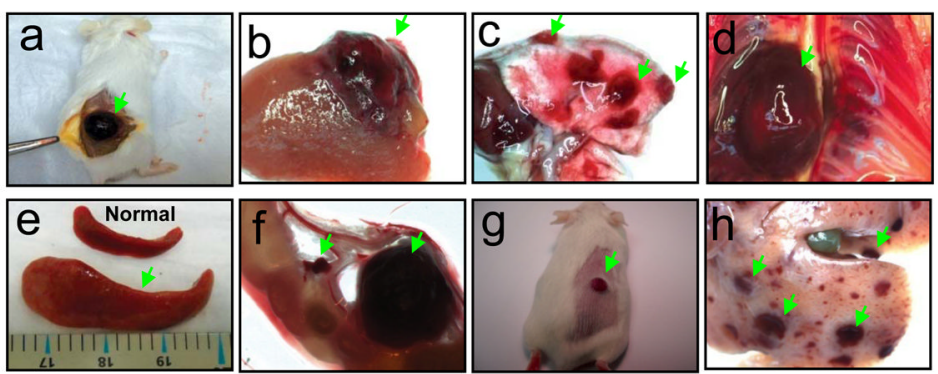

B
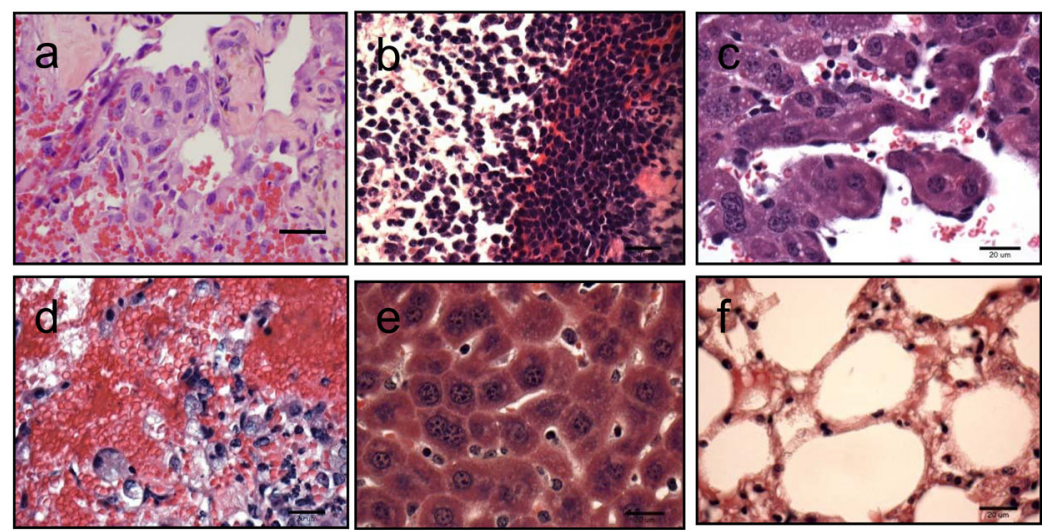

C
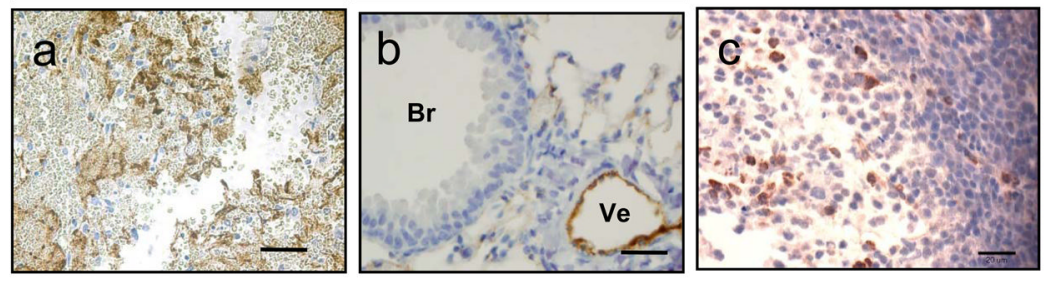

D
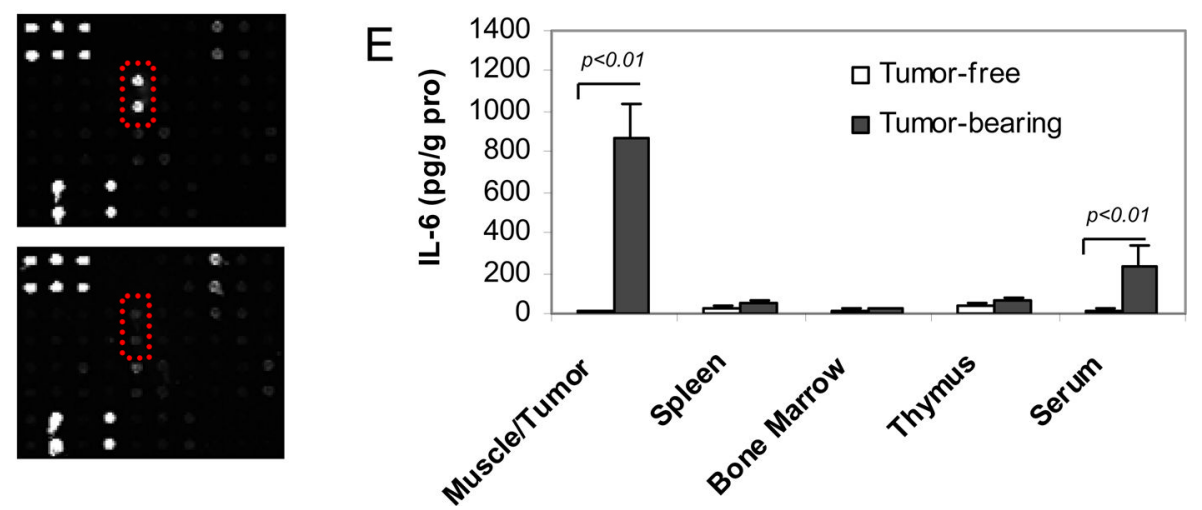

Figure 2.

Loss of $\mathrm{p} 16^{\mathrm{Ink} 4 \mathrm{a}} / \mathrm{p} 19^{\text {Arf }}$ causes angiosarcoma. A, Ink4a/Arf deficient FVB mice exhibit spontaneous angiosarcoma in muscle (a), liver (b), lung (c) and chest wall (d), spleen (e), intestine (f), skin (g) and exhibit metastasis to the liver (h). Green arrows indicate angiosarcoma lesions. B, H\&E staining of angiosarcoma lesions shows blood filled sacs in muscle (a), spleen (b), liver (c) and lung (d) in comparison to normal tissues of liver (e) and lung (f). C, Von Willebrand factor (VWF) immunohistochemistry staining of paraffinembedded tumor tissue sections reveals disordered, infiltrative vasculature in angiosarcoma (a) compared to a normal vessel in the lung (b). CD31 immunohistochemistry staining for angiosarcoma involving the spleen. (c). Ve, vessel; Br, bronchiole; $20 \mu \mathrm{m}$ scale bar as 
indicated. D, serum cytokines profiles (32 cytokines) in angiosarcoma tumor-bearing mice ( $n=6$, upper panels) in contrast to tumor-free mice ( $n=6$, lower panels). Duplicate spots within the rectangle of the dotted line are IL- 6 blots. E, IL-6 levels in the tissues of angiosarcoma from tumor-bearing mice $(n=6)$ or muscle from non-tumor bearing mice $(n=6)$ were determined by ELISA. 
A

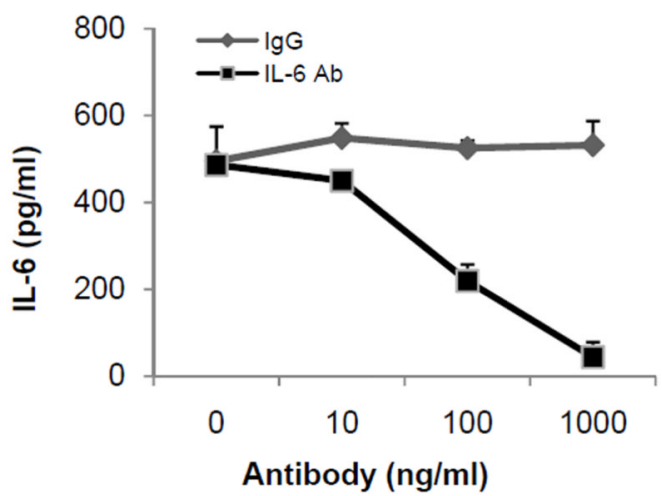

B

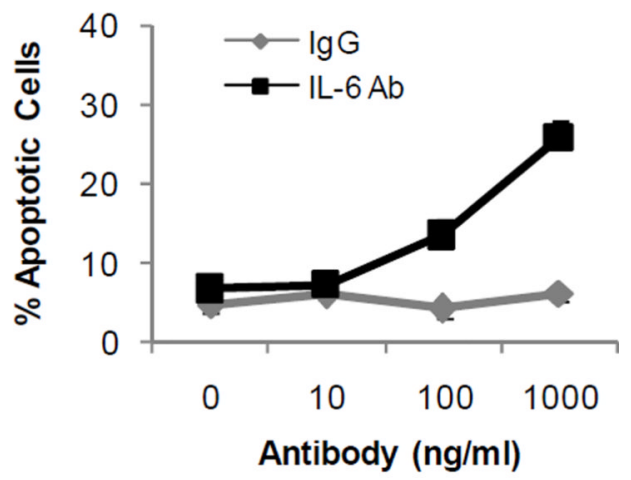

C

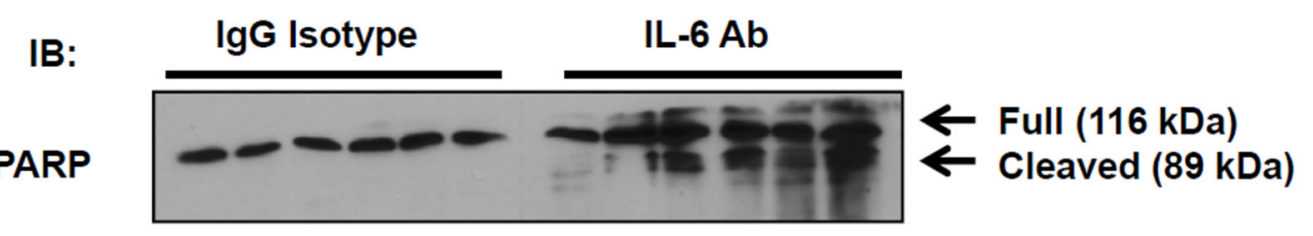

$\beta$-Actin

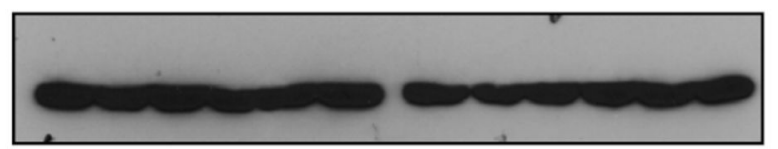

D

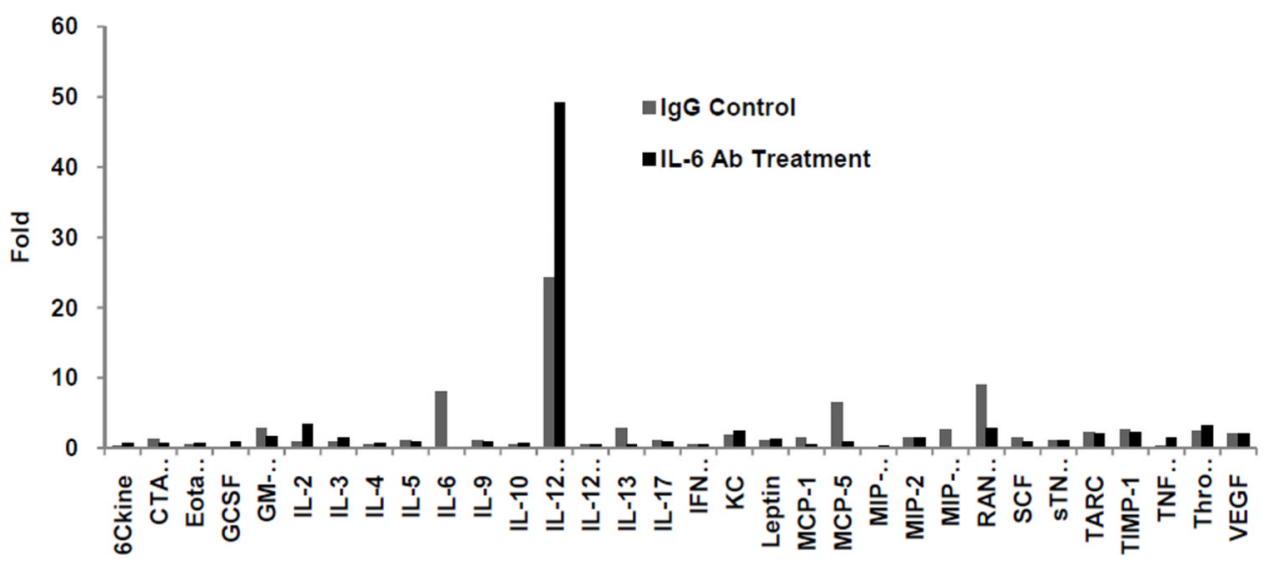

Figure 3.

Neutralization of IL-6 attenuated angiosarcoma cell growth. A, neutralization of IL-6 in vitro. $5 \times 10^{4}$ angiosarcoma cells cultured in serum-free medium were treated with increasing concentrations of anti-IL-6 antibody or control isotype IgG for 3 days. Supernatant IL-6 was determined by ELISA. B, IL-6 favors anti-apoptosis. All treated cells in A were collected, stained with SR-FLICA and analyzed by FACS. The SR-FLICA positive/7-AAD negative early apoptotic cells were graphed $(p<0.01)$. C, anti-IL-6 induced apoptosis in vivo. FVB strain (6 mice/group) were xenografted with subcutaneous angiosarcoma. When tumor size reached around $180 \mathrm{~mm}^{3}$, IL-6 antibody at $500 \mu \mathrm{g}$ per mouse was intraperitoneally administered every other day. The same amount of IgG1 treatment was used as a isotype 
control. After 6 days treatment, the tumor lysates were subjected to immunoblotting for the cleaved PARP to reflect the apoptotic status. D, cytokine profile of serum from anti-IL-6 versus control IgG treated angiosarcoma bearing mice. Angiosarcoma xenografted mice were given anti IL- 6 treatment or IgG insope treatment as control. After 6 days treatment, serum cytokine profile was analyzed using a cytokine array (32 cytokines) approach. The value of cytokines was normalized with the serum sample from tumor-free is expressed as fold difference. 


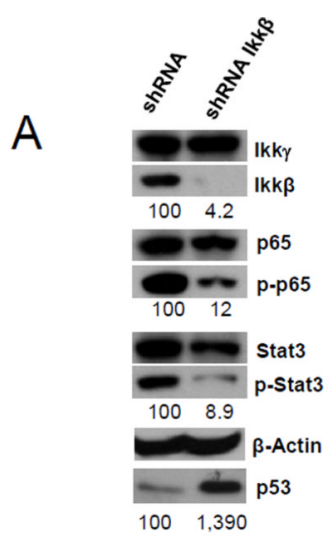

B
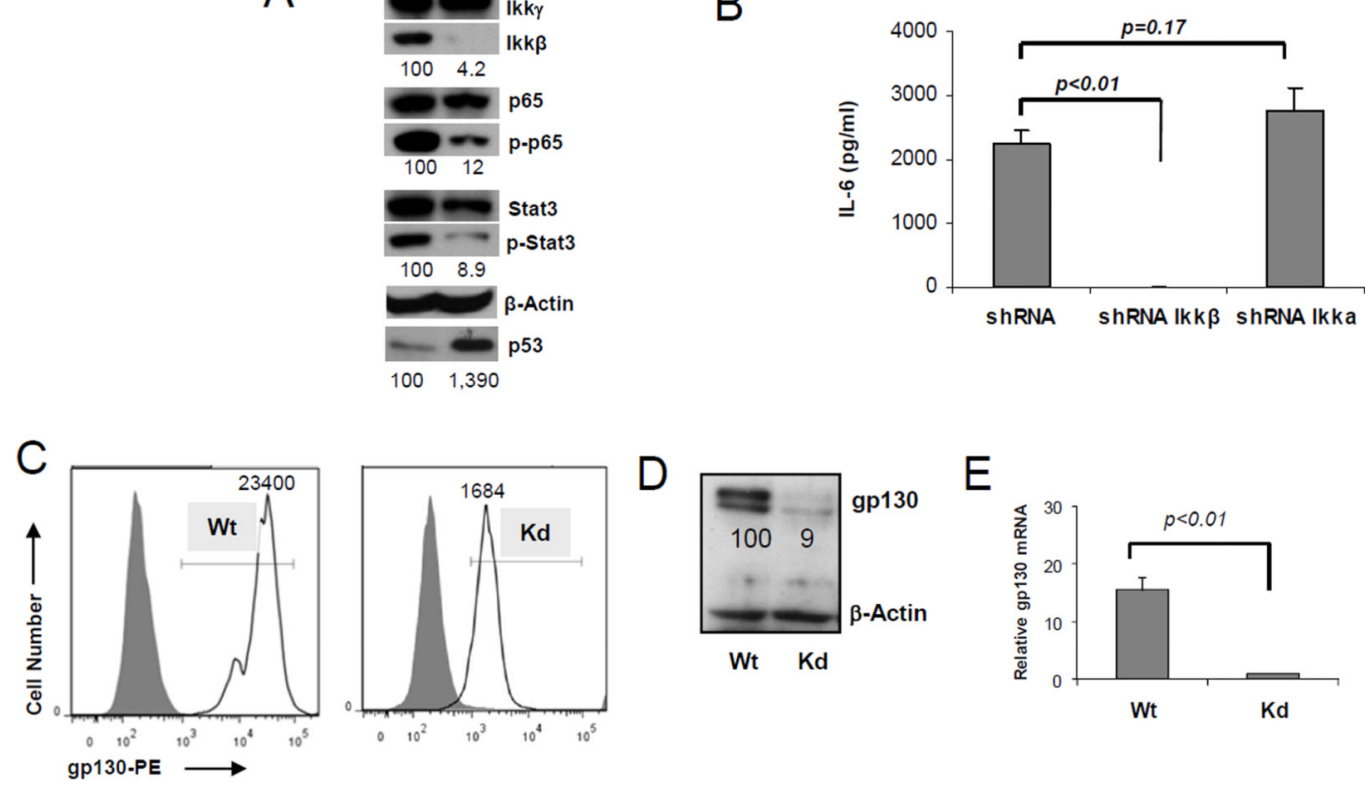

E

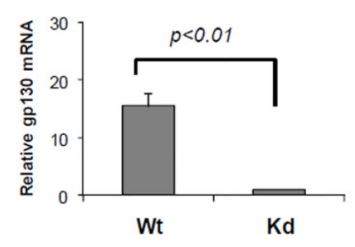

$\mathrm{F}$

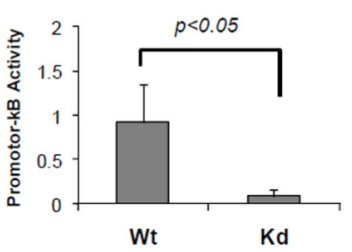

G

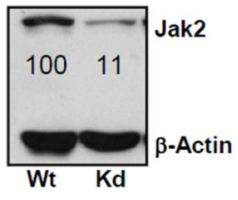

$\mathrm{H}$
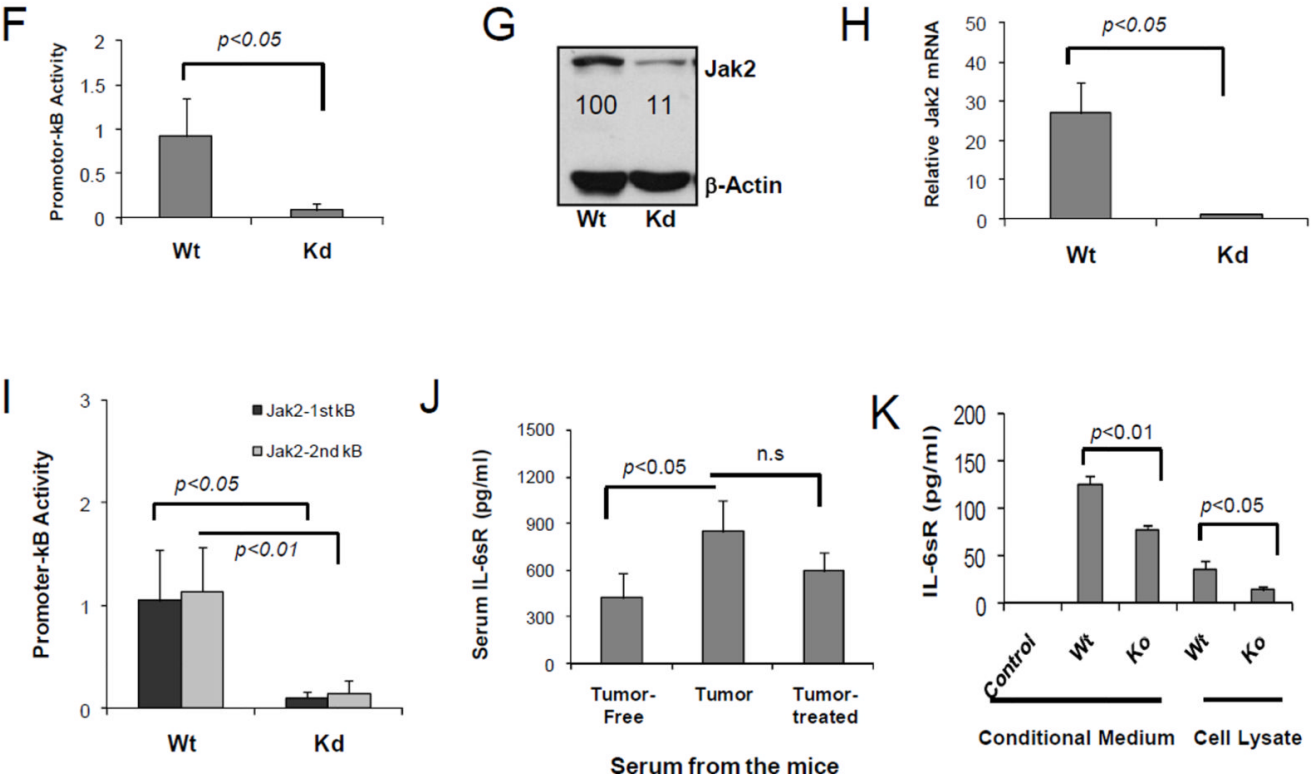

Figure 4.

Ikk $\beta$ is required for angiosarcoma progression. A, knockdown of Ikk $\beta$ effects p65 and STAT phosphorylation and p53 expression. Lysates from Ikk $\beta$ knock-down or wt angiosarcoma cells were immunoblotted to detect Ikk $\beta$, Ikk $\gamma$ and the phosphorylation of NF- $\kappa B / p 65$ (Ser536), Stat3 (Tyr705). The densitometry values below the bands represent the percentage change of phospho-protein as compared with total protein (100\%) blotted with specific antibody. B, ablation of IL-6 production by Ikk $\beta$ interference. Angiosarcoma cells stably expressing shRNA vector alone, shRNA Ikk $\beta$ or shRNA Ikka were cultured in $1 \mathrm{ml}$ serum-free medium. After 24-h culture supernatant IL-6 concentration was determined by ELISA. Data are representative of at least 3 independent experiments. C, NF- $\kappa B$ 
regulates gp130 expression. Angiosarcoma cells were stained with PE-conjugated gp130 antibody (upper panels) and evaluated by FACS analysis for cells with Ikk $\beta$ wild type (Wt) or Ikk $\beta$ knockdown $(\mathrm{Kd})$. The solid peak is negative staining and the open peak is gp130 positive staining. D, immunoblotting of cytosol gp130 and $\beta$-actin was performed in the cells. E, quantitation of gp130 mRNA by qRT-PCR. F, NF- $\mathrm{kB}$ regulation of gp130 transcription. NF- $\mathrm{\kappa B}$ regulation of GP130 was evaluated with a reporter construct comprising multiple copies of the putative NF- $\mathrm{kB}$ element of gp130 promoter linked to a Gaussian luciferase reporter gene. G, expression of Jak2 protein in the Ikk $\beta$-wt or Ikk $\beta$ depleted angiosarcoma cells was immunoblotted. H, quantitation of Jak2 mRNA by RTqPCR. I, NF- $\kappa \mathrm{B}$ regulation of Jak2 transcription. Jak2 promoter NF- $\kappa \mathrm{B}$ sites were examined for its transcriptional activity using a Gaussian luciferase reporter. J, IL-6sR is present in the serum of mice. Sera were collected from angiosarcoma tumor free FVB Ink4a/Arf-/- mice $(n=4)$, angiosarcoma tumor-bearing FVB Ink4a/Arf-/- mice $(n=4)$, and angiosarcoma tumor-bearing FVB Ink4a/Arf-/- mice $(n=4)$ treated with BMS-345541. The IL6sR concentration in the serum was determined by ELISA. K, IL-6sR levels in conditioned medium or cell lysates from angiosarcoma cells $\left(2 \times 10^{6}\right)$ stably expressing shRNA vector or shRNA-Ikk $\beta$ based on ELISA from three independent experiments and expressed as mean \pm SEM. Medium not exposed to cells was the negative control. Wt refers to cells transfected with the non-silencing shRNA (wild type Ikk $\beta$ ); Kd refers Ikk $\beta$ knockdown. Statistical analysis was by Student's t-test. 

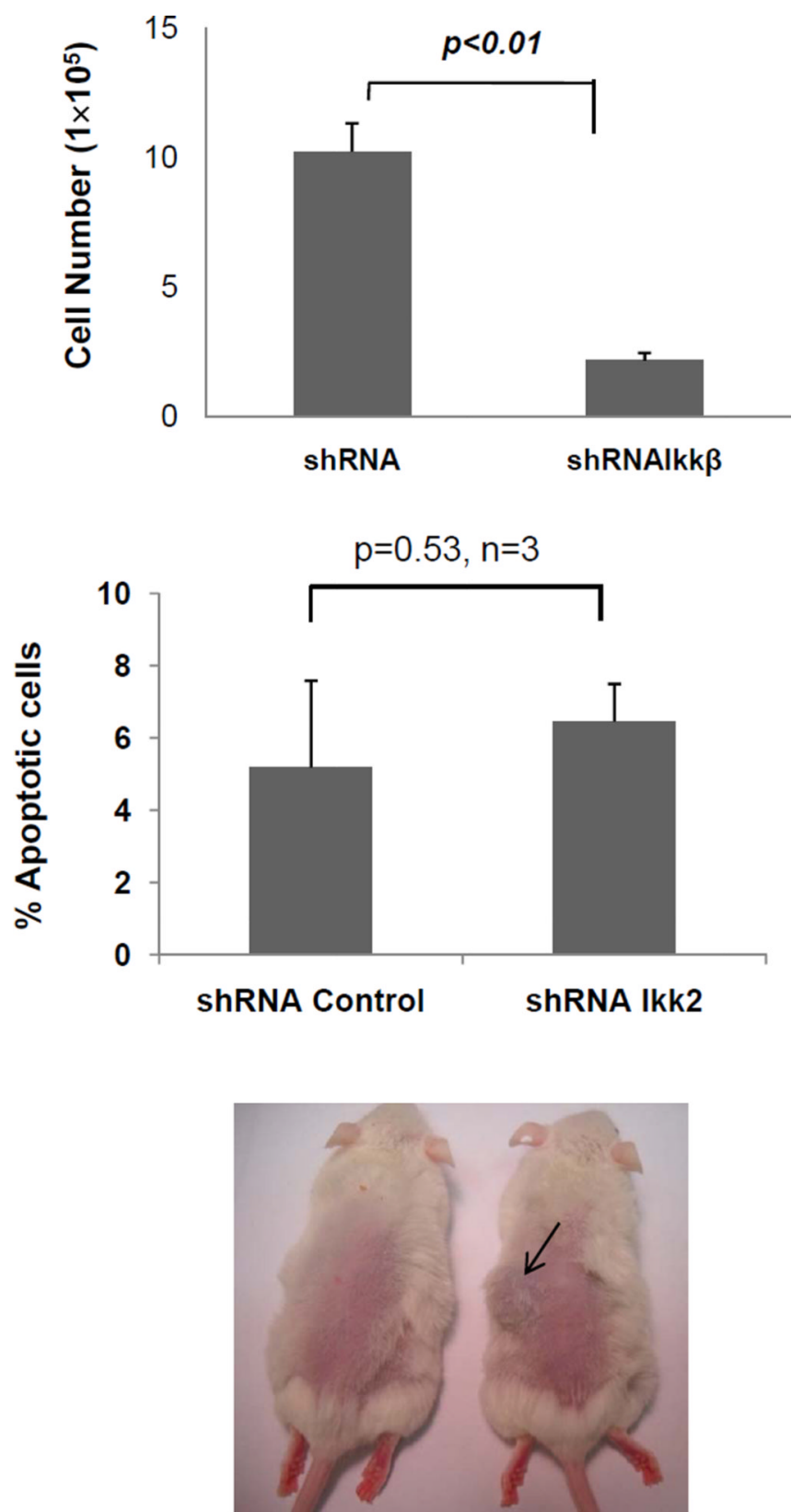

shRNA Ikk $\beta$

shRNA

\begin{tabular}{lll}
\hline Tumor rate & $0 / 5$ & $5 / 5$ \\
\hline
\end{tabular}

Figure 5.

Targeting of $I k k \beta$ retarded the growth of angiosarcoma cells. A, angiosarcoma cells expressing shRNA Ikk $\beta$ or vector control shRNA were cultured 5 days, adherent cells were trypsinized and counted, then growth rate was graphed $(p<0.01, \mathrm{n}=6)$. shRNA indicates cells stably expressing shRNA vector alone; shRNA Ikk $\beta$ indicates cells stably expressing the shRNA Ikk $\beta$. B, apoptosis of angiosarcoma cells stably expressing shRNA Ikk $\beta$ or shRNA empty vector were evaluated for apoptosis using the Total cytotoxicity Kit (Immunochemistry Technologies, LLC) and FACS analysis. The early apoptotic cells are defined as those that are SR-FLICA ${ }^{\mathrm{TM}}$ positive, but 7-AAD negative. The difference between Ikk $\beta$ knockdown and control cells was statistically analyzed $(p=0.53, n=3)$ based 
on the t-test. C, depletion of Ikk $\beta$ ablated angiosarcoma formation. Ink4a/Arf-deficient angiosarcoma cells $\left(1 \times 10^{7}\right)$ with or without $I k k \beta$ silenced were subcutaneously inoculated into FVB strain wild type mice (5 mice/group). Twenty-one days after inoculation, all five mice in the shRNA control group exhibited angiosarcoma tumors, while no tumor formation was observed in the shRNA Ikk $\beta$ group. Representative photograph of mouse with angiosarcoma lesion (arrow). 
A

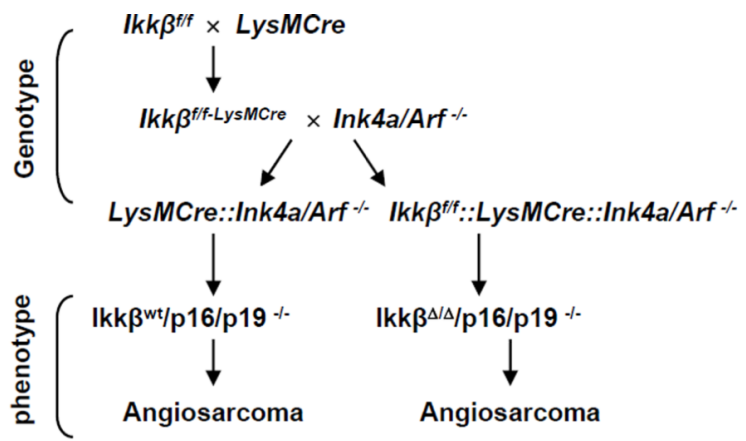

B
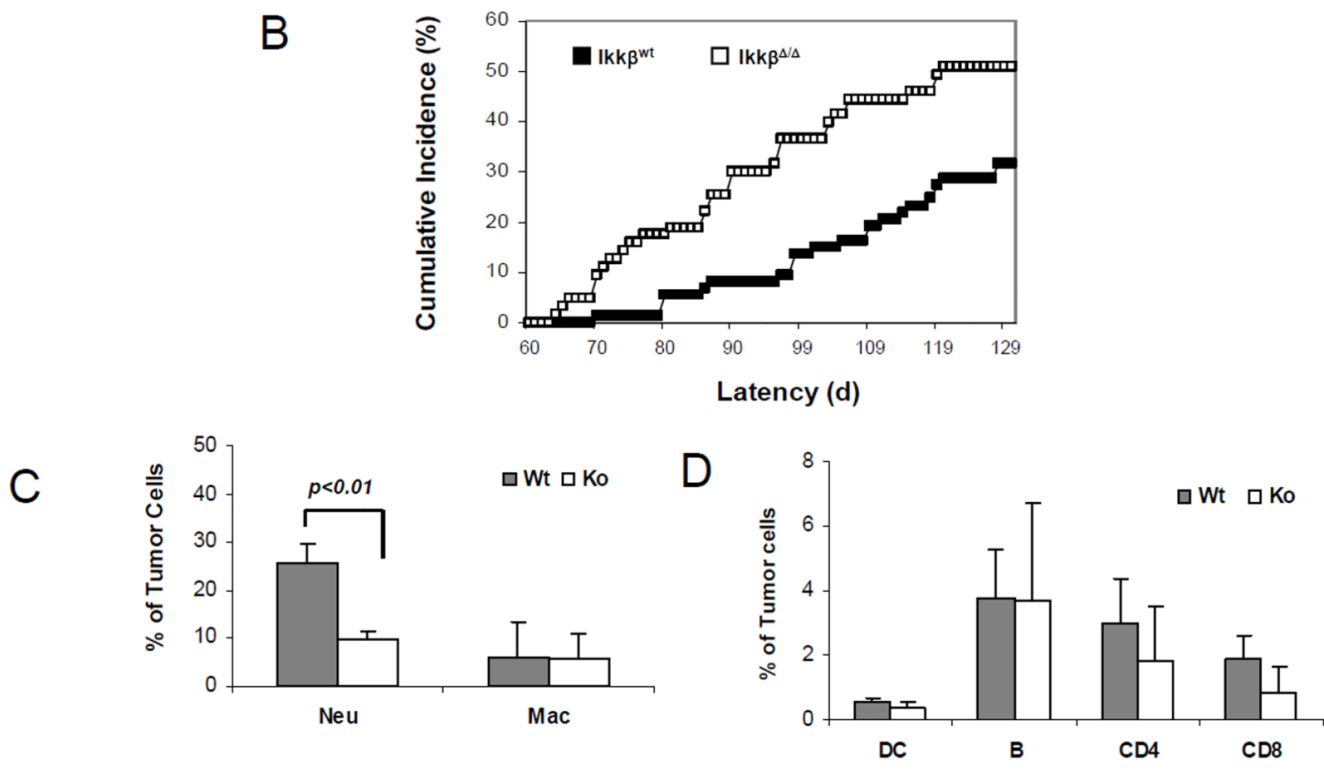

E
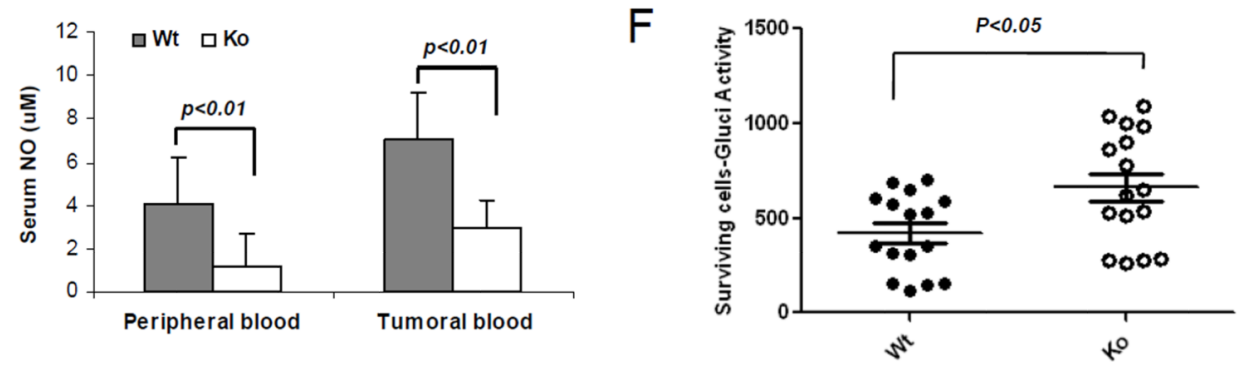

Figure 6.

Myeloid Ikk $\beta$ is linked to host-defense against angiosarcoma growth. A,generation of myeloid Ikk $\beta$ knockout lineage. Ikk $\beta^{f / f}$ mice crossed with myeloid-specific LysMCre mice and FVB Ink4a/Arf-/- mice as described in Materials and methods. FVB mice lacking of

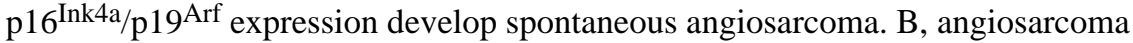
development was followed in 63 LysM-Cre- $I k k \beta^{\Delta / \Delta}$ mice and $73 I k k \beta^{w t}$ mice on the Ink4a/ $\mathrm{Arf}^{-/-}$background and cumulative incidence was statistically analyzed ( $p<0.003$, Log-rank test). C, myeloid Ikk $\beta$ deficiency reduces anti-tumor cytotoxicity. Angiosarcoma tumors arising in $I k k \beta^{w t}$ or LysM-Cre- Ikk $\beta^{\Delta / \Delta}$ mice were dissociated, stained with fluorochromeconjugated antibody, and analyzed by flow cytometry. The percentage of neutrophils in the 
infiltrate was significantly higher in the tumors of $I k k \beta^{w t}$ mice than in LysM-Cre $I k k \beta^{\Delta / \Delta}$ mice $(p<0.01, \mathrm{n}=5)$. There was no statistical difference in macrophage distribution in the tumors between $I k k \beta^{w t}$ and $I k k \beta^{\Delta / \Delta}$ mice. Neu, neutrophils; Mac, macrophages; Wt, Ikk $\beta^{w t}$ mice; Ko, LysM-Cre-Ikk $\beta^{\Delta / \Delta}$ mice. D, the cells isolated in Fig $5 \mathrm{C}$ were simultaneously stained for leukocyte markers. There was no statistical difference in dendritic cells (DC); B cells (B); CD4 T cells, or CD8 T cells between $I k k \beta^{w t}$ and LysM-Cre- $I k k \beta^{\Delta / \Delta}$ in tumors. E, NO levels in blood. The serum NO was determined as described in Methods from peripheral blood in tumor-bearing $I k k \beta^{\Delta / \Delta}$ mice compared with $I k k \beta^{w t}$ mice $(p=0.008$ and $p=0.0008$, respectively; $n=8$ mice per group). F, In vivo cytotoxicity assay. Angiosarcoma cells $\left(1 \times 10^{7}\right)$ stably expressing non-secreted truncated Gaussian luciferase (18-285aa) were injected intraperitoneally into $I k k \beta^{W t}$ and LysM-Cre- $I k k \beta^{\Delta / \Delta}$ mice. After $18 \mathrm{~h}$, peritoneal cells were collected, lysed and luciferase activity was determined to reflect the $\%$ viable cells. Tumor cell survival in LysM-Cre-Ikk $\beta^{\Delta / \Delta}$ mice was compared to $I k k \beta^{w t}$ mice $(p<0.01, \mathrm{n}=16)$. Wt, Ikk $\beta^{w t}$ mice; Ko, Ikk $\beta^{\Delta / \Delta}$ mice. 

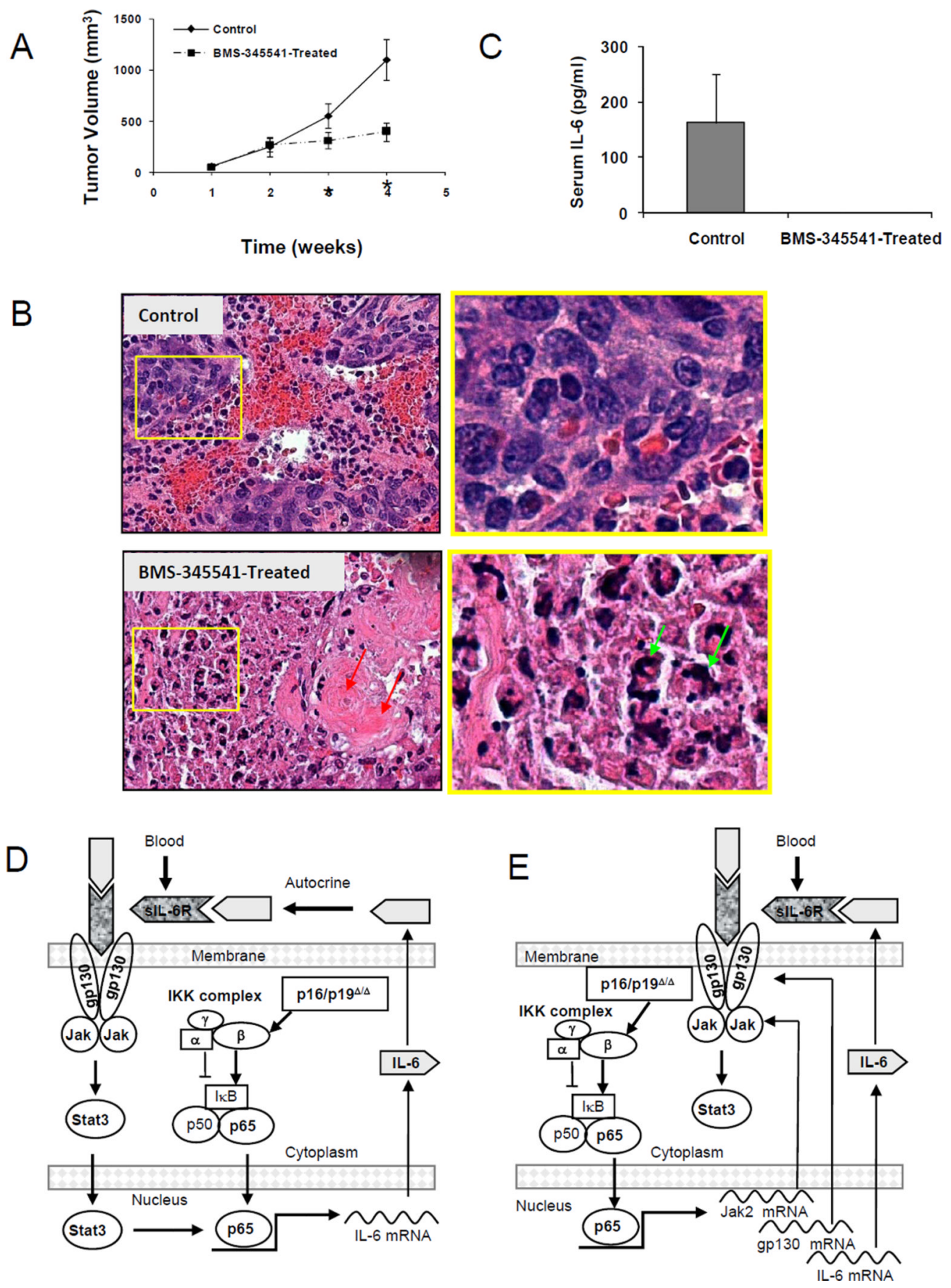

Figure 7.

Systemic targeting of Ikk $\beta$. A, angiosarcoma cells $\left(2 \times 10^{6}\right)$ derived from a spontaneous angiosarcoma in FVB mouse deficient for Ink4a/Arf were injected subcutaneously into FVB mice (10 mice per group). When tumors reached a size of $\sim 250 \mathrm{~mm}^{3}$, mice received BMS-345541 or vehicle control for 2 weeks. Data are expressed as mean \pm SEM and analyzed by the two-sample t-test with Satterthwaite's approximation. ${ }^{*} p<0.01$ refers to a statistically significant difference between the treatment and control groups. B, H\&E staining of tumor tissue sections from angiosarcoma xenografts in mice shown in Figure 7A. The green arrow indicates nuclear condensation, the red arrow indicates proliferation of benign stromal/fibroblastic cells and the yellow rectangle indicates the enlarged area on the 
right panel. C, serum IL-6 levels in mice treated with BMS345541 or vehicle control. Blood samples were collected at the end of experiment 7A and serum IL-6 concentrations were determined by ELISA. D, schematic of proposed molecular mechanism links Ink4a/Arf null mice and angiosarcoma. NF- $\kappa B$ extrinsically regulates the Stat 3 pathway. Loss of $\mathrm{p} 16^{\text {Ink4a/ }}$ p19Arf in endothelial cells leads to consequent up-regulation of NF- $\kappa$ B activity, overproduction of IL-6, and activation of the gp130/Jak/Stat3 pathway. E, NF- $\kappa B$ intrinsically regulates the Stat 3 pathway. Ikk $\beta / N F-\kappa B$ transcriptionally controls expression of gp130/ Jak2 upstream of Stat3. 